\title{
Structure-Property Relationships in Graphene-Based Strain and Pressure Sensors for Potential Artificial Intelligence Applications
}

Zewei Luo ${ }^{1,+}$, Xiaotong Hu ${ }^{1,+}{ }^{+}$, Xiyue Tian ${ }^{1}$, Chen Luo ${ }^{1}$, Hejun $\mathrm{Xu}^{1}{ }^{1}$, Quanling Li ${ }^{1}$, Qianhao Li ${ }^{1}$, Jian Zhang ${ }^{1,2}$, Fei Qiao ${ }^{3, *}$, Xing Wu ${ }^{1,2, *}$, V. E. Borisenko ${ }^{4,5}$ and Junhao Chu ${ }^{1,3}$

1 Shanghai Key Laboratory of Multidimensional Information Processing, Department of Electronic Engineering, East China Normal University, Shanghai 200241, China; 52181213021@stu.ecnu.edu.cn (Z.L.); 10172100328@stu.ecnu.edu.cn (X.H.); 51181213032@stu.ecnu.edu.cn (X.T.);

52161213022@stu.ecnu.edu.cn (C.L.); 52151213012@stu.ecnu.edu.cn (H.X.);

51161213021@stu.ecnu.edu.cn (Q.L.); 51171213058@stu.ecnu.edu.cn (Q.L.); jzhang@ee.ecnu.edu.cn (J.Z.); jhchu@mail.sitp.ac.cn (J.C.)

2 Shanghai Institute of Intelligent Electronics \& Systems, Fudan University, Shanghai 200433, China

3 Department of Electronic Engineering, Tsinghua University, 30 Shuangqing Road, Beijing 100084, China

4 Belarusian State University of Informatics and Radioelectronics, P. Browka 6, 220013 Minsk, Belarus; borisenko@bsuir.by

5 National Research Nuclear University MEPhI (Moscow Engineering Physics Institute), Kashirskoe Shosse 31, 115409 Moscow, Russia

* Correspondence: qiaofei@tsinghua.edu.cn (F.Q.); xwu@ee.ecnu.edu.cn (X.W.); Tel.: +86-21-5434-5399 (X.W.)

+ these authors contributed equally to this work.

Received: 22 January 2019; Accepted: 6 March 2019; Published: 12 March 2019

\begin{abstract}
Wearable electronic sensing devices are deemed to be a crucial technology of smart personal electronics. Strain and pressure sensors, one of the most popular research directions in recent years, are the key components of smart and flexible electronics. Graphene, as an advanced nanomaterial, exerts pre-eminent characteristics including high electrical conductivity, excellent mechanical properties, and flexibility. The above advantages of graphene provide great potential for applications in mechatronics, robotics, automation, human-machine interaction, etc.: graphene with diverse structures and leverages, strain and pressure sensors with new functionalities. Herein, the recent progress in graphene-based strain and pressure sensors is presented. The sensing materials are classified into four structures including 0D fullerene, 1D fiber, 2D film, and 3D porous structures. Different structures of graphene-based strain and pressure sensors provide various properties and multifunctions in crucial parameters such as sensitivity, linearity, and hysteresis. The recent and potential applications for graphene-based sensors are also discussed, especially in the field of human motion detection. Finally, the perspectives of graphene-based strain and pressure sensors used in human motion detection combined with artificial intelligence are surveyed. Challenges such as the biocompatibility, integration, and additivity of the sensors are discussed as well.
\end{abstract}

Keywords: graphene; strain sensor; pressure sensor; structure-property; artificial intelligence

\section{Introduction}

Wearable devices can be worn directly on the user, embedded in clothing, or implanted in the body to detect human health motion [1-5]. These flexible sensors can monitor physiological parameters such as pulse, blood pressure, body temperature, and heart rate signals of the human body with high efficiency and subtle discomfort, as a part of advanced devices [6-12]. 
Wearable sensors possess a wide range of applications in wearable devices due to their light weight, good ductility, flexibility, and suitability for large-area manufacturing processes [13-15]. However, in order to mount easier the wearable sensors on the human skin for real-time human motion detection, several performance and parameter requirements need to be fulfilled. Lightweight, flexibility, stretchability, durability, biocompatibility, and low power consumption are crucial properties for wearable sensors [16-18].

In general, researchers take advantage of the superior electrical, chemical, and optical properties of nanomaterials for signal sensing, combining mechanical, flexibility, stretchability, and durability of polymers to make the sensors flexible. These novel sensors are mainly strain sensors [19-21] and pressure sensors [22,23]. Nowadays, various wearable sensors have been widely developed in health monitoring, human motion detection, device system integration, human-machine interactions, and artificial intelligence [24-28].

Graphene demonstrates outstanding characteristics such as perfect mechanical strength, good electrical properties, chemical stability, and high thermal conductivity [29,30] which are all required for the sensing materials of wearable mechanical sensors. Due to ultrahigh sensitivity, graphene is one of the best nanomaterials for pressure and strain sensing applications [31,32]. It is critical and necessary to further study and develop graphene-based strain and pressure sensors. As shown in Figure 1, graphene-based strain and pressure sensors have achieved conspicuous progress. Over the last decade, graphene-based sensors have been categorized into three conversion mechanisms such as resistive, capacitance, and piezoelectricity, showing a vigorous development trend [33-35].

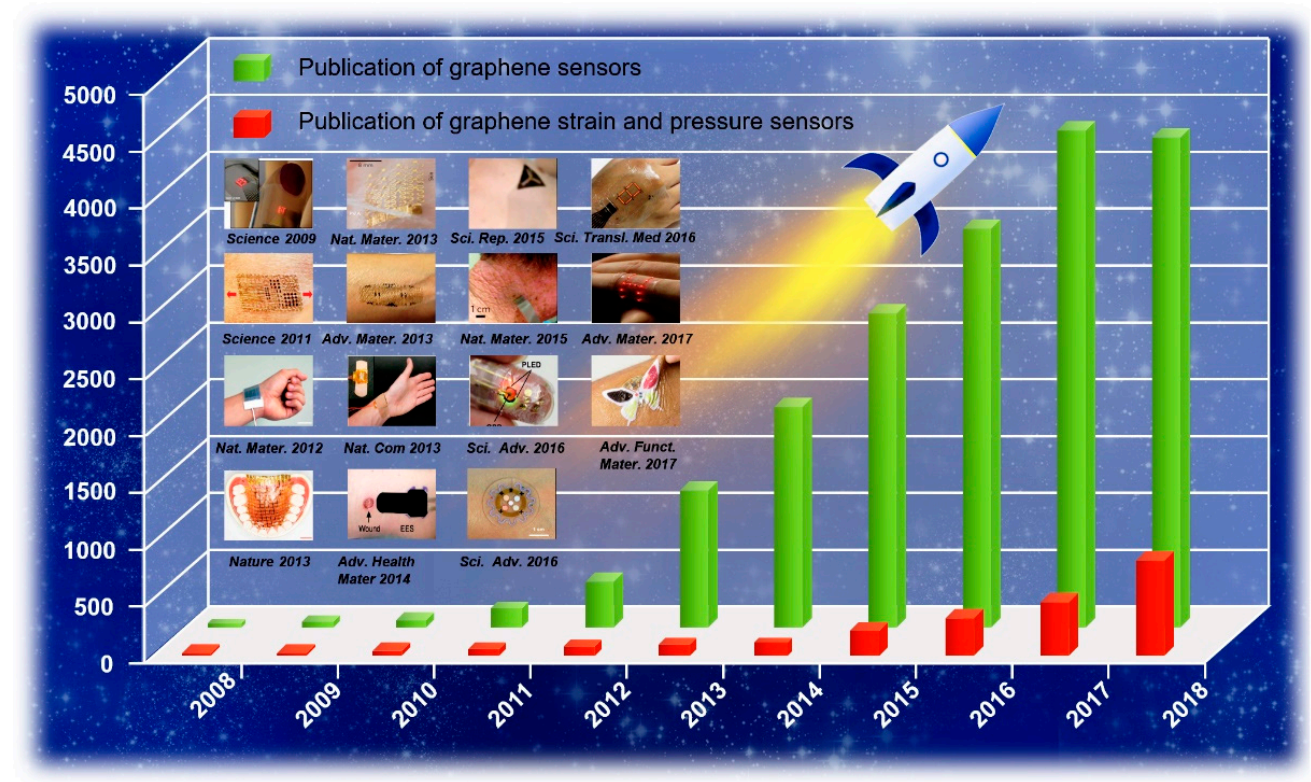

Figure 1. Trends in the development of graphene-based sensors and graphene-based strain and pressure sensors. The data is from the Web of Science. Hundreds of papers have been published, and a selected subset is represented since 2008 [36-52]. Copyright 2009, American Association for the Advancement of Science; Copyright 2011, American Association for the Advancement of Science; Copyright 2008, Wiley; Copyright 2012, Nature Publishing Group; Copyright 2013, Nature Publishing Group; Copyright 2013, Nature Publishing Group; Copyright 2013, Wiley; Copyright 2013, Nature Publishing Group; Copyright 2014, Wiley; Copyright 2015, Nature Publishing Group; Copyright 2015, Wiley; Copyright 2016, American Association for the Advancement of Science; Copyright 2016, American Association for the Advancement of Science; Copyright 2016, American Association for the Advancement of Science; Copyright 2017, Wiley; Copyright 2017, Wiley.

In this review, we place particular emphasis on structure-property and the potential applications of the latest graphene-based strain and pressure sensors. The fundamentals and transduction mechanisms 
of the graphene-based strain and pressure sensors are described. As shown in Figure 2, we highlight the latest progress and breakthrough in graphene-based strain and pressure sensors classified in four structures including 0-dimensional (0D) fullerene [53,54], 1-dimensional (1D) fiber [55-57], 2-dimensional (2D) film [58-61], and 3-dimensional (3D) porous structure [62-65] to guarantee various properties. Herein, the $0 \mathrm{D}$ structure graphene-based sensors are defined as the sensors that use a OD composite structure in the sensing layer. The 1D structure graphene-based sensors are defined as sensors that use fibers like composite structures in the sensing layer. The 2D structure focuses on sensors that use 2D planar film. The 3D structure refers to a porous structure. Graphene is used as the main sensing material in the above structures. The above "composite structure" means that there are other materials in the sensing layer except graphene [66,67]. Additionally, major technical parameters in graphene-based strain and pressure sensors such as linearity, sensitivity, and hysteresis properties for accurate sensing are described. Graphene-based strain and pressure sensors show various applications including device system integration, health monitoring, human motion detection, human-machine interaction, and artificial intelligence $[68,69]$. Finally, we summarize recent development trends and application forecasts, especially the challenges in combination with artificial intelligence [70-75].

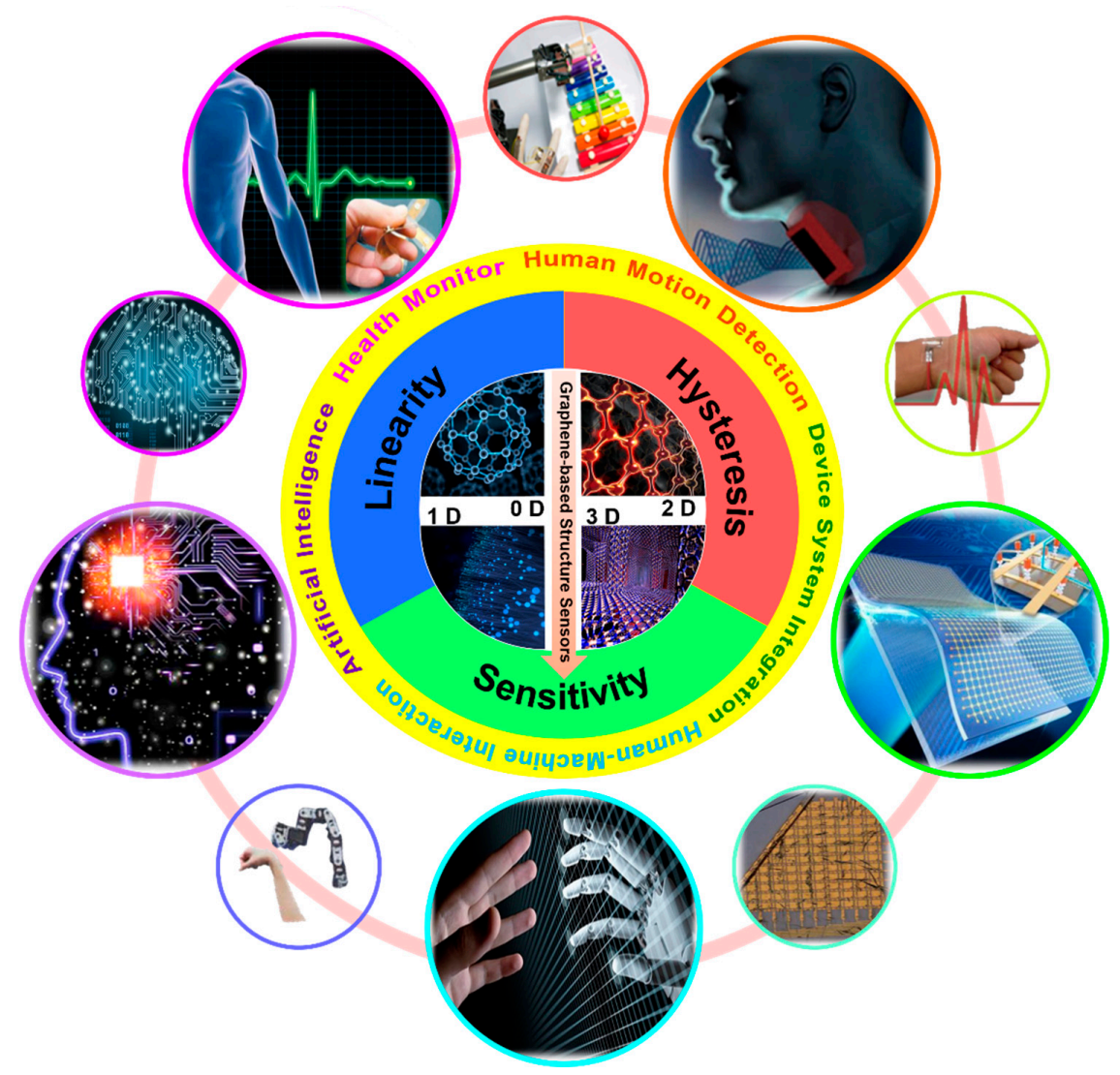

Figure 2. Overview of the graphene-based strain and pressure sensors in the various fabrications of the structures and wide range of potential applications [76-79]. Copyright 2015, Wiley; Copyright 2014, Nature Publishing Group; Copyright 2016, Nature Publishing Group; Copyright 2017, Nature Publishing Group; Copyright Google Images.

\section{Fundamentals of Graphene-Based Strain and Pressure Sensors}

\subsection{Classification of Graphene-Based Strain and Pressure Sensors}

The excellent characteristics and the efficient productive ability of graphene make it a suitable choice for the sensing materials of strain and pressure sensors. Graphene-based strain and pressure sensors exhibit one of the highest sensitivities and gauge factor [80-82]. During the last few 
years, researchers have made great progress in graphene-based strain and pressure sensors [83]. In graphene-based strain and pressure sensors, graphene [84-87] is familiarly used as active material to sense physical signal including strain and pressure $[88,89]$. Due to the excellent electrical conductivity, graphene materials are frequently used as a conducting layer or electrodes of graphene-based strain and pressure sensors. Furthermore, various graphene structures such as 0D fullerene, 1D fiber, 2D film, and 3D porous structure guarantee the multifunction of graphene-based strain and pressure sensors for applications in different scenarios. As shown in Figure 3, traditional transduction methods of graphene-based strain and pressure sensors include resistive [90,91], capacitance [92,93], and piezoelectricity $[94,95]$. The details of these transduction methods are presented in this section.

Resistive sensors convert external forces into a variation of resistance, which can be directly detected by a pre-built detection circuit through changes in the electrical signals. It obtains a resistive sensing signal through the change of the resistance [96]. Due to a simple measurement method and the large scope of applications [97], resistive sensors have been widely used. As shown in Figure 3a, the resistive effect is generated by an applied external force changing the conductive path of the sensing material, which changes the resistance [98-100]. The resistive effect is an inherent characteristic of graphene which makes it a desired sensing material for strain and pressure sensors. The high conductivity and favorable mechanical properties of graphene enable the graphene-based resistive sensor to have ultrahigh sensitivity [101]. As a common type of strain and pressure sensor, the advantages of graphene-based resistive sensors are a wide detection range, simple equipment construction, and signal testing [84,102-104]. Due to these advantages, graphene-based resistive sensors have attracted great attention. Moreover, graphene-based resistive sensors also demonstrate unlimited potential in frontier applications such as human motion detection and artificial intelligence.

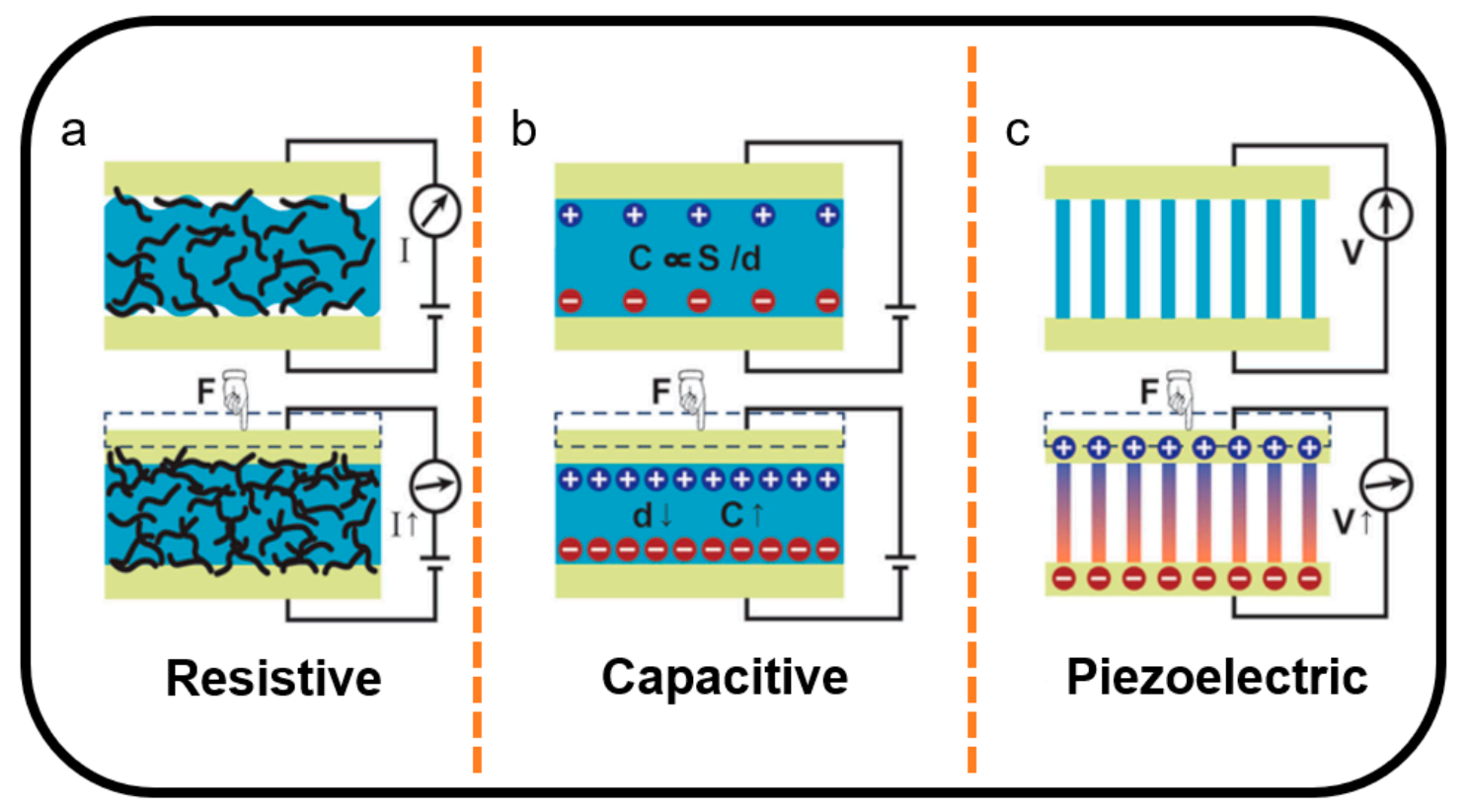

Figure 3. Schematic illustrations of the transduction methods: (a) resistive, (b) capacitive, and (c) piezoelectric [79,96,105,106]. Copyright 2015, American Association for the Advancement of Science.

The capacitive sensor is another traditional type of graphene-based strain and pressure sensor $[107,108]$. Capacitive sensors can detect different forms of force by converting mechanical stimulus signals into displacement signals $[109,110]$. The change of displacement causes a change in capacitance. As shown in Figure 3b, capacitive sensors detect force variation in different directions by changing the effective area of the sensing material and the spacing of the parallel plates to obtain an electrical signal [101]. The sensitivity and stability of capacitive sensors mainly depend on the favorable compression properties of the dielectric layer. Due to the excellent conductivity, favorable mechanical 
properties, and large specific surface area, graphene is the ideal electrical conductor and electrode for capacitive sensors [111]. The extreme sensitivity of a capacitive sensor to weak changes makes it widely used in the detection of static or tiny forces [112-115].

Piezoelectric materials are special materials which can generate electrical charges under mechanical stress. The piezoelectric effect is caused by the presence of an oriented non-centrosymmetric crystal structure in the piezoelectric material, resulting in an electric dipole moment [116]. The higher the piezoelectric coefficient of a piezoelectric material, the higher the energy conversion efficiency it has [117]. Therefore, highly sensitive and fast-responding piezoelectric materials are widely used in pressure sensors that convert pressure into electrical signals. Previous research has shown that single-layer graphene can achieve a negative piezoelectric effect, and two-layer and multi-layer graphene can achieve a positive piezoelectric conductance effect $[118,119]$. Graphene-based piezoelectric sensors have been used to detect continuous static pressure signals and perpendicular vibrations due to their ultrafast response time and ultrahigh sensitivity [120,121].

\subsection{Major Parameters of Graphene-Based Strain and Pressure Sensors}

Different fabrication procedures and structures (0D fullerene, 1D fiber, 2D film, 3D porous structure) in graphene-based strain and pressure sensors result in various properties and functions for applications. It is crucial to list and classify the parameters of graphene-based strain and pressure sensors. These parameters can be used to visually distinguish the characteristics and functions of the sensors. For graphene-based strain and pressure sensors, there are several major parameters including sensitivity, gauge factor (mostly for the strain sensor), detection range, linearity, hysteresis, response time, and relaxation time. It is worth noting that sensitivity exists in pressure sensors while the gauge factor exists in the strain sensors.

The sensitivity of pressure sensors generally refers to the ratio between the variables involved in the output and input signals. For graphene-based pressure sensors with different transduction mechanisms, the input and output signals are different. For instance, the sensitivity of resistive pressure sensors is calculated by dividing the relevant variation of resistance by the variation of the applied force, as shown in Formula (1). In the same way, sensitivities of capacitive and piezoelectric pressure sensors correspond to capacitance and voltage, respectively.

$$
\text { Sensitivity }=\left|\frac{\Delta R / R_{0}}{\Delta F}\right|
$$

Gauge factor, which makes no sense to pressure sensors, is an important parameter for strain sensors. Gauge factor (GF), also named strain factor, of a strain sensor is the ratio of the relevant change in electrical resistance $R$, to the mechanical strain $\varepsilon$, which means this parameter is only significant for the resistive strain sensor. (Formula (2))

$$
G F=\left|\frac{\Delta R / R_{0}}{\varepsilon}\right|
$$

Linearity is an important indicator to describe the static characteristics of a sensor. It is used to characterize the parameters whose actual characteristics do not match the fitted line. In certain conditions, the ratio of the maximum deviation between the sensor calibration curve to the fitted line and the full-scale output is called linearity, also known as nonlinearity error [122]. For the graphene-based strain and pressure sensors, it is still a technical challenge to balance the relationship between sensitivity and linearity [123,124]. At present, researchers still cannot achieve both high sensitivity and good linearity for graphene-based strain and pressure sensors, which needs further study [125-127].

The phenomenon that the input and output characteristic curves do not coincide during the input quantity changes from small to large and from large to small is called hysteresis. It refers to the degree of inconsistency between the forward stroke characteristics and the reverse stroke characteristics of the 
sensor under the same operating conditions [128,129]. Hysteresis is another important indicator of sensor performance. Therefore, various factors affecting hysteresis must be strictly controlled in the production process of the sensor. For the graphene-based strain and pressure sensors, when the sensor is stretched or compressed and released, graphene flakes need several seconds or milliseconds to return to their original position, by which occurs hysteresis $[130,131]$. High hysteresis reduces the durability and robustness of the sensor. Hence hysteresis is an important parameter for graphene-based strain and pressure sensors.

The detection range of strain and pressure sensors is the maximum and minimum values that can be accurately measured. Mechanical sensors are commonly used to measure tiny disturbances, especially in biomedical applications. Therefore, the detection range is also an important parameter to use to judge whether the measurement of the sensor is effective.

Response time and relaxation time are two parameters to describe the speed of the response of the sensor at the loading and unloading process, respectively. Response time and relaxation time are important technical indicators of the sensor, reflecting the response speed of the sensor to the signal; the smaller the value, the faster the response. The response time determines the frequency of the signal sampling. Thus, it is crucial for the sensor.

Major parameters for recent graphene-based strain and pressure sensor research are summarized and classified in Tables 1 and 2, respectively. The "Sensing Materials" column identifies the materials used in the sensing layer of the sensors. The "Transduction Mechanisms" column describes the transduction mechanisms and structure of the sensors $[108,132,133]$. The other columns are for the major parameters of the sensors [134,135].

Table 1. Different parameters of the graphene-based strain sensors.

\begin{tabular}{|c|c|c|c|c|c|}
\hline Sensing Materials & $\begin{array}{l}\text { Transduction } \\
\text { Mechanisms }\end{array}$ & Gauge Factor & $\begin{array}{c}\text { Detection } \\
\text { Range }\end{array}$ & $\begin{array}{c}\text { Response } \\
\text { Time }\end{array}$ & Reference \\
\hline $\begin{array}{c}\text { 0D-1D-2D } \\
\text { nanocomposite }\end{array}$ & OD Resistive Strain & $2392.9(\varepsilon=62 \%)$ & $0-62 \%$ & - & [136] \\
\hline PDCY-rGO & 1D Resistive Strain & $35(\varepsilon=0.2 \%)$ & $0.2-100 \%$ & $<100 \mathrm{~ms}$ & [137] \\
\hline CSF & 1D Resistive Strain & $37.5(\varepsilon=250-500 \%)$ & $0-500 \%$ & $<70 \mathrm{~ms}$ & [138] \\
\hline AgNW/Graphene & 1D Capacitance Strain & - & $5-200 \%$ & $<1 \mathrm{~ms}$ & [139] \\
\hline PMSCSS & 2D Resistive Strain & $647(\varepsilon=0.14 \%)$ & $0-0.22 \%$ & $0.625 \mathrm{~ms}$ & [140] \\
\hline GWF & 2D Resistive Strain & $500(\varepsilon=2 \%)$ & $0-40 \%$ & $<30 \mathrm{~ms}$ & [141] \\
\hline BGF/BGFM & 3D Resistive Strain & $6.5(\varepsilon=10 \%)$ & $0-50 \%$ & - & [142] \\
\hline Graphene/PDMS & 3D Resistive Strain & $55.1(\varepsilon=25 \%)$ & $0-64 \%$ & $400 \mathrm{~ms}$ & [143] \\
\hline Graphene & 1D Resistive Strain & $42.8(\varepsilon=9 \%)$ & $0-24 \%$ & $1.1 \mathrm{~s}$ & [144] \\
\hline Graphene & 2D Resistive Strain & $1037(\varepsilon=2 \%)$ & $0-4 \%$ & - & [145] \\
\hline
\end{tabular}

Table 2. Different parameters of the graphene-based pressure sensors.

\begin{tabular}{cccccc}
\hline Sensing Materials & $\begin{array}{c}\text { Transduction } \\
\text { Mechanisms }\end{array}$ & Sensitivity & $\begin{array}{c}\text { Detection } \\
\text { Range }\end{array}$ & $\begin{array}{c}\text { Response } \\
\text { Time }\end{array}$ & Reference \\
\hline PTNWs/Graphene & 1D Piezoelectric Pressure & $9.4 \times 10^{-3} \mathrm{kPa}^{-1}$ & $0-1.5 \mathrm{kPa}$ & $5-7 \mathrm{~ms}$ & {$[34]$} \\
rGO/PVDF & 1D Resistive Pressure & $15.6 \mathrm{kPa}^{-1}$ & $1.2 \mathrm{~Pa}-60 \mathrm{kPa}$ & $5 \mathrm{~ms}$ & {$[146]$} \\
rGO & 2D Capacitance Pressure & $0.8 \mathrm{kPa}^{-1}$ & $0.24 \mathrm{~Pa}-4 \mathrm{kPa}$ & $<100 \mathrm{~ms}$ & {$[111]$} \\
LSG & 2D Resistive Pressure & $0.96 \mathrm{kPa}^{-1}$ & $10-100 \mathrm{kPa}$ & $0.4 \mathrm{~ms}$ & {$[147]$} \\
ACNT/Graphene & 2D Resistive Pressure & $19.8 \mathrm{kPa}^{-1}$ & $0.6 \mathrm{~Pa}-0.3 \mathrm{kPa}$ & $<16.7 \mathrm{~ms}$ & {$[148]$} \\
WG & 2D Resistive Pressure & $6.92 \mathrm{kPa}^{-1}$ & $0-5 \mathrm{kPa}$ & - & {$[149]$} \\
Graphene hybrid & 2D Resistive Pressure & $0.032 \mathrm{kPa}^{-1}$ & $0-100 \mathrm{kPa}$ & $10 \mathrm{kHz}$ & {$[150]$} \\
MX/rGO & 3D Resistive Pressure & $22.56 \mathrm{kPa}^{-1}$ & $0-3.5 \mathrm{kPa}$ & $<200 \mathrm{~ms}$ & {$[151]$} \\
rGO/PU & 3D Resistive Pressure & $0.26 \mathrm{kPa}^{-1}$ & $0-10 \mathrm{kPa}$ & - & {$[86]$} \\
G-S & 3D Capacitance Pressure & $1.04 \mathrm{kPa}^{-1}$ & $0-20 \mathrm{kPa}$ & $<5 \mathrm{~ms}$ & {$[152]$} \\
rGO/PI/HT & 3D Resistive Pressure & $0.36 \mathrm{kPa}^{-1}$ & $0.2 \mathrm{~Pa}-14 \mathrm{kPa}$ & $<80 \mathrm{~ms}$ & {$[153]$} \\
OPG & 3D Resistive Pressure & $313.23 \mathrm{kPa}^{-1}$ & $0-4 \mathrm{kPa}$ & $28 \mathrm{~ms}$ & {$[154]$} \\
Graphene & 2D Resistive Pressure & $17.2 \mathrm{kPa}^{-1}$ & $0-20 \mathrm{kPa}$ & - & {$[155]$} \\
Graphene & 2D Capacitance Pressure & $0.33 \mathrm{kPa}^{-1}$ & $0-5 \mathrm{kPa}$ & $<20 \mathrm{~ms}$ & {$[112]$} \\
Graphene & 3D Resistive Pressure & $110 \mathrm{kPa}^{-1}$ & $0.2 \mathrm{~Pa}-75 \mathrm{kPa}$ & $<30 \mathrm{~ms}$ & {$[156]$} \\
\hline
\end{tabular}




\section{A Graphene-Based Inorganic Pressure Sensor in Various Dimensionalities}

\subsection{Zero Dimensional}

Herein, the 0D structure graphene-based sensors are defined as the sensors that use a 0D composite structure in the sensing layer, and OD fullerene as a lubricant and graphene as the main sensing material. The structural characterizations of 0D structure strain and pressure sensors are shown in Figure 4a,b. The $0 \mathrm{D}$ fullerene structure is incompact before the strain and pressure as shown in Figure $4 \mathrm{a}$. In the loading state, the 0D fullerene structure becomes compact (Figure 4b).

a

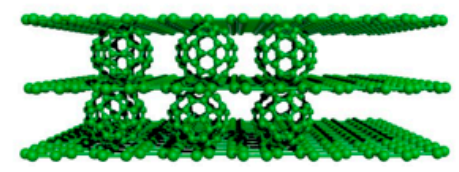

b

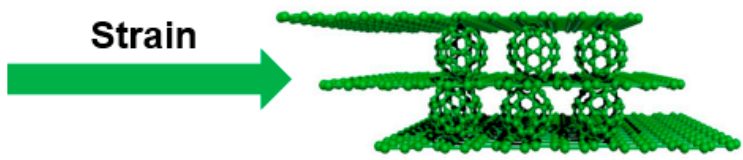

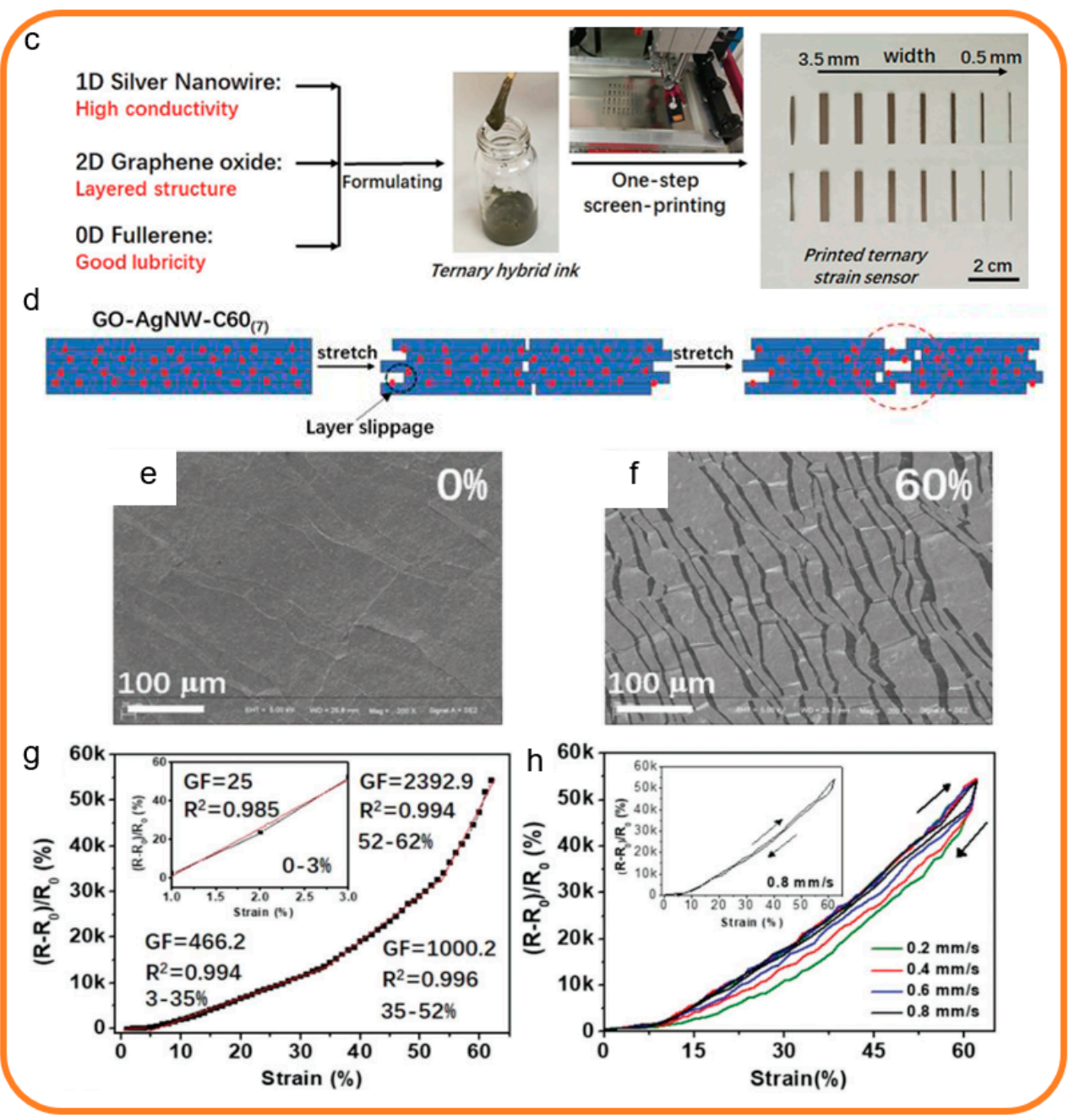

Figure 4. Fabrication processes and structural characterization of OD structure strain sensors [136]. Copyright 2018, Wiley. (a) The structure diagram for 0D strain sensors based on 0D fullerene structure before stretch. (b) The structure diagram of the 0D strain based on 0D fullerene structure after stretch. (c) The preparation process of this OD structure strain sensor. (d) Schematic illustration of a sensing mechanism for films under stretching. (e) Surface SEM images for sensing films at $0 \%$ applied strains. (f) Surface SEM images for sensing films at 60\% applied strains. (g) The Gauge factor (GF) and linear behavior of the strain sensor. (h) The hysteresis of the strain sensor. 
Chen et al. proposed a 0D structure graphene-based strain sensor which has brilliant properties including good linearity, high sensitivity, and low hysteresis [136]. As shown in Figure 4c, this 0D structure strain sensor was assembled by screen-printing from a ternary aqueous ink on the stretchable substrate. Figure $4 \mathrm{~d}$ shows the sensing mechanism of this $0 \mathrm{D}$ structure strain sensor. The stretching in the sensing layer undergoes slippage between sensing material layers. Due to this sensor being fabricated from ternary composites, it is worth researching what role the 0D structure plays in the sensor. As shown in Figure 4e,f, applying different degrees of stress to the film leads to microcrack formation on the surface of the film and spreads evenly, which demonstrates the impact of the $0 \mathrm{D}$ structure on the sensing mechanism. It serves as a lubricant to reduce friction between adjacent layered materials in the sensor. In addition, this $0 \mathrm{D}$ structure strain sensor exhibits both large stretchability and ultrahigh gauge factor. As shown in Figure 4g, at up to $62 \%$ strain, the gauge factor of this sensor reaches 2392.9. This $0 \mathrm{D}$ structure strain sensor also exhibits negligible hysteresis at $0.8 \mathrm{~mm} \mathrm{~s}^{-1}$ strain rate, as shown in Figure $4 \mathrm{~h}$.

Due to the complicated preparation process and limited role in sensing materials, there are rare studies on the 0D structure graphene-based strain and pressure sensors. It is difficult to support a complete sensing structure alone for $0 \mathrm{D}$ structure graphene, which is usually used as a lubricant to improve sensor performance. Most 0D structure graphene-based strain and pressure sensors have negligible hysteresis and ultrahigh sensitivity due to the structural lubrication of the $0 \mathrm{D}$ structure. However, its linearity still needs to be improved.

\subsection{One Dimensional}

Herein, the 1D structure graphene-based sensors are defined as sensors that use fibers like composite structure in the sensing layer, and graphene as the main sensing material. In general, to fabricate the 1D structure, the polymer material is used as a substrate and the graphene is deposited on the polymer by chemical or physical methods. The representative structural characterizations of 1D structure strain and pressure sensors are shown in Figure 5a,b. The 1D fibers are tortuous before the strain and pressure as shown in Figure 5a. In the loading state, the 1D fiber structure becomes unbent (Figure 5b) [157-162].

In a typical case, $\mathrm{Xu}$ et al. described a flexible graphene-based pressure sensor by using a novel material called $\mathrm{PbTiO}_{3}$ nanowires (PTNWs), which has been applied in human motion detection and health monitoring [34]. Compared to the traditional chemical vapor deposition (CVD)-grown graphene-based pressure sensor, this graphene-based pressure sensor shows a higher sensitivity. The fabricating processes of this 1D structure graphene pressure sensor are shown in Figure 5c. A Raman spectrum of graphene shows a small D peak at $1350 \mathrm{~cm}^{-1}$, which depicts low-density defects or disordered carbon in graphene. The distributive diameter of the PTNWs is about $500 \mathrm{~nm}$, with the lengths reaching up to $10 \mu \mathrm{m}$. This sensor takes advantage of the polarization charges in $\mathrm{PbTiO}_{3}$ nanowires to stimulate carrier mobility of the graphene, which drastically increases the sensitivity. As shown in Figure 5d, this sensor exhibits both good linearity ranging from 0 to $1400 \mathrm{~Pa}$ and ultrahigh sensitivity up to $9.4 \times 10^{-3} \mathrm{kPa}^{-1}$. The response time and relaxation time are $5 \mathrm{~ms}$ and $7 \mathrm{~ms}$, respectively, as shown in Figure 5e, which indicates negligible hysteresis of this sensor.

In the other representative case, Oopark et al. proposed different types of graphene-based strain sensors possessing large stretchability, high sensitivity, and special negative sensing response, which can also be used in human motion detection and health monitoring [163]. As shown in Figure 5f, these graphene-based fiber strain sensors were fabricated from a graphene nanoplatelet dispersion and a poly vinyl alcohol solution using the layer-by-layer assembly technique. The SEM images of the graphene-based strain sensors without strain and with strain demonstrate the characterization of the 1D structure, which determines the properties of the graphene-based strain sensors. Figure $5 \mathrm{~g}, \mathrm{~h}$ show the wide detection scale up to $150 \%$, excellent linearity stretching up to $100 \%$, high sensitivity, and negligible hysteresis of these sensors. Especially, the wool yarn graphene-based strain sensor demonstrates peculiar negative resistive property. 
a

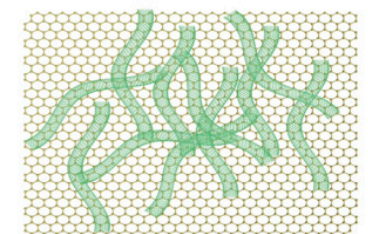

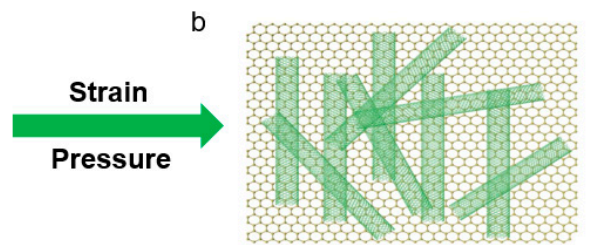
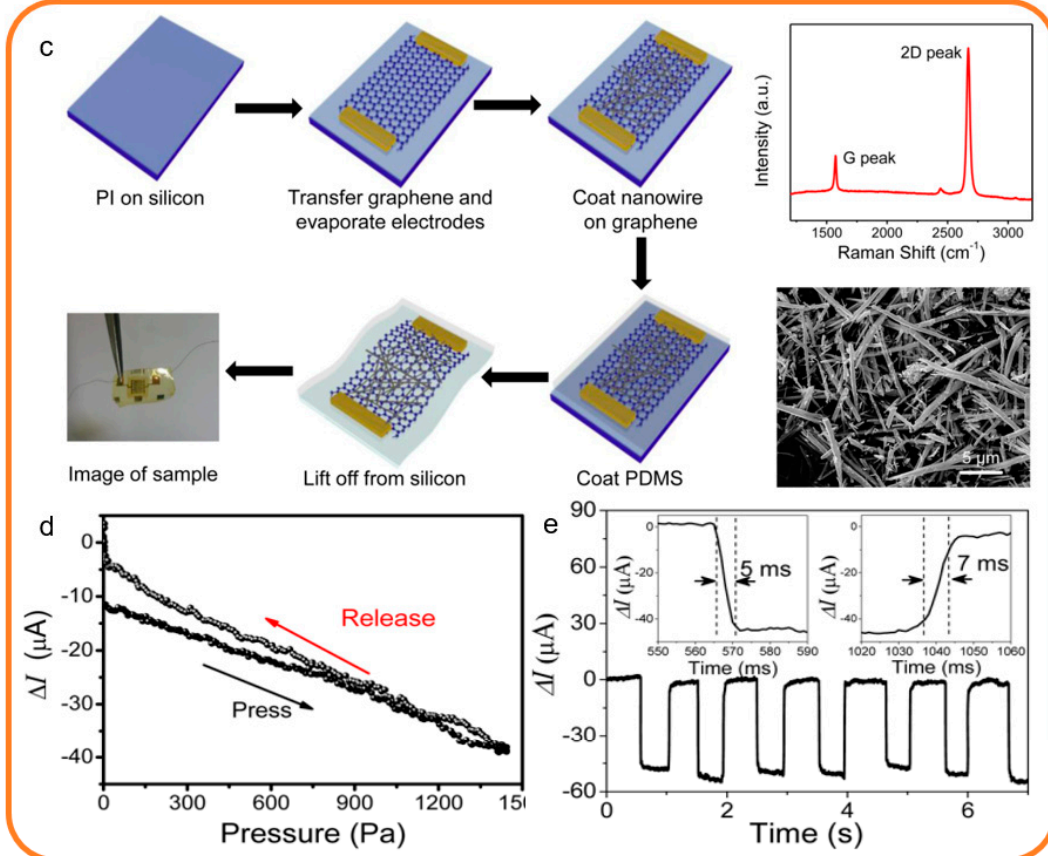

Coat nanowire
on graphene

l

Raman Shift $\left(\mathrm{cm}^{-1}\right)$
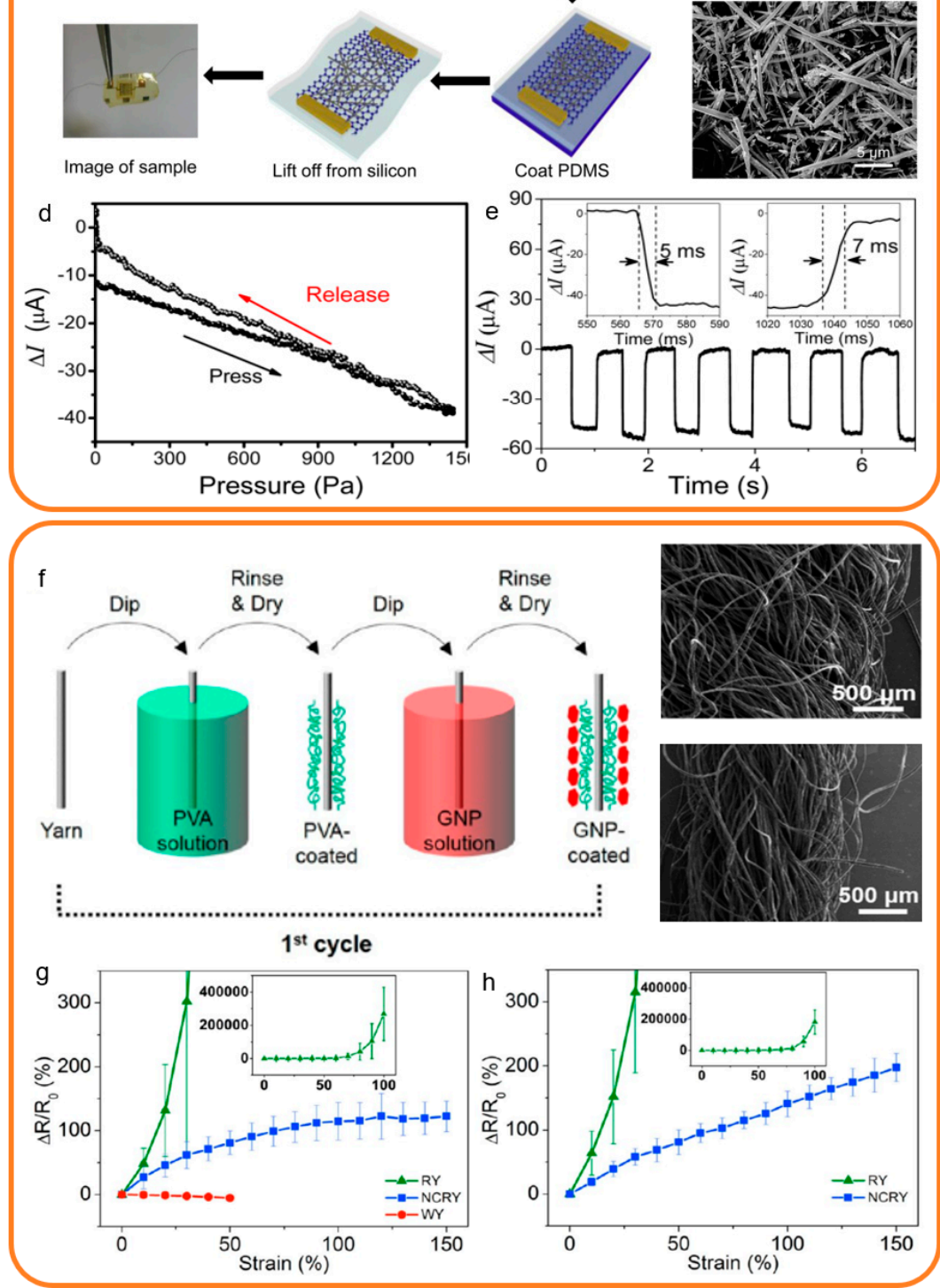

Figure 5. Fabrication processes and structural characterization of 1D structure strain and pressure sensors [34,163]. Copyright 2017, American Chemical Society; Copyright 2015, American Chemical Society. (a) The structure diagram of the 1D strain and pressure sensors based on 1D graphene structure before the strain and pressure. (b) The structure diagram of the 1D strain and pressure sensors based on 1D graphene structure after the strain and pressure. (c) The fabrication process of a 1D structure pressure sensor and its representations. (d) The sensitivity and linearity of this pressure sensor. (e) The hysteresis of this pressure sensor. (f) The fabrication process of a 1D structure strain sensor and its representations. (g) The sensitivity and linearity of three types of strain sensors. (h) The function of the Polydimethylsiloxane (PDMS) coating. 
The 1D structure is a common form of graphene-based strain and sensors, which can be used in most traditional transduction methods. However, the dimensional limitations cause anisotropy limitations. In general, the 1D structure graphene-based strain and sensors can only be pressured or stretched in one direction. Most 1D structure graphene-based strain and pressure sensors have negligible hysteresis and favorable linearity. However, the detection scale of the 1D structure sensors is limited and the sensitivity is relatively tiny compared to other structures.

\subsection{Two Dimensional}

Herein, we present the 2D structure focus on sensors that use 2D planar film and graphene as the main sensing material. The 2D structure can be obtained by methods such as suction filtration, CVD growth, chemical synthesis, etc. The classical structural characterization of 2D structure strain and pressure sensors is shown in Figure 6a,b. The 2D graphene layer structure is fluffy before the strain and pressure as shown in Figure 6a. In the loading state, the 2D graphene layer structure becomes impacted (Figure 6b) [164-168].

In a typical case, Ren et al. proposed a paper of the 2D graphene-based pressure sensor which has wide potential in the use of human motion detection and health monitoring [155]. This 2D graphene-based pressure sensor has ultrahigh sensitivity, stable repeatability, and good hysteresis. As shown in Figure 6c, this 2D graphene-based strain sensor was fabricated by several simple steps. The graphene 2D structure of this paper like the 2D graphene-based pressure sensor can be clearly observed in the optical image of graphene paper. The optical image of the cross-section shows the folds and collapses in the graphene film, which makes it so called graphene paper. The sensing mechanism of this paper like the 2D graphene-based pressure sensor is the many voids and pores between the graphene layers. When pressure is applied, the indirect contact dots of the graphene sheets rapidly increase, and the resistance rapidly decreases, which is the main reason why this sensor has ultrahigh sensitivity up to $17.2 \mathrm{kPa}^{-1}$ in the range of $0-2 \mathrm{kPa}$ (Figure $6 \mathrm{~d}$ ). Figure $6 \mathrm{e}$ shows the response time is about $60 \mathrm{~ms}$ which indicates negligible hysteresis of this sensor.

In the other representative case, a high sensitivity and negligible hysteresis capacitive graphene-based pressure sensor is proposed by Sun et al. which can be used in human-machine interactions and artificial intelligence [111]. As shown in Figure $6 \mathrm{f}$, this 2D graphene-based strain sensor is fabricated by individual reduced graphene oxide materials in six steps. The SEM images apparently indicate the 2D graphene layers structure in sensing materials and substrates and the graphene electrodes demonstrate homogeneity and smoothness. By changing the density of the sensing material, the detection range of this 2D graphene-based strain sensor can be changed. In Figure 6g, it is shown that this $2 \mathrm{D}$ graphene-based strain sensor has ultrahigh sensitivity up to $0.8 \mathrm{kPa}^{-1}$ at extreme low-pressure regime about $0-1 \mathrm{kPa}$. This sensor also exhibits fast response time about $100 \mathrm{~ms}$ as shown in Figure $6 \mathrm{~h}$.

The 2D structure is the most hackneyed form of graphene-based strain and sensors, which can be applied in all transduction methods. The 2D structure graphene-based strain and pressure sensors can be pressured or stretched in all directions in the plane. According to different needs, the 2D structure graphene-based strain and pressure sensors can detect large or tiny forces. Most 2D structures have negligible hysteresis, favorable linearity, and above-average sensitivity. Even if the 2D structure graphene-based strain and sensors have the above benign properties, it is impossible to generate a large deformation by a tiny force because the sensing layer is essentially a thin film. 

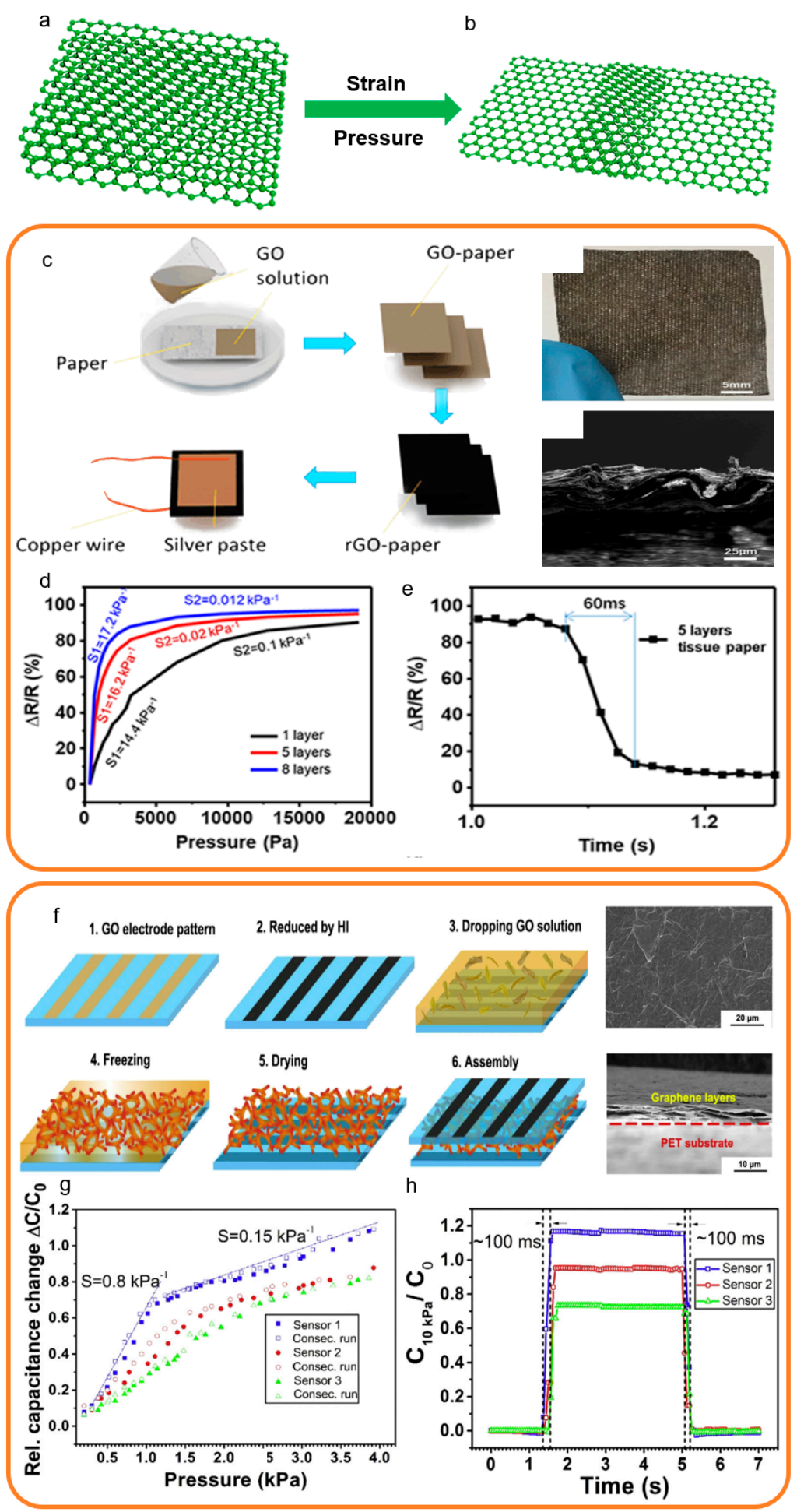

Figure 6. Fabrication processes and structural characterization of 2D structure strain and pressure sensors [111,155]. Copyright 2017, Elsevier; Copyright 2017, American Chemical Society. (a) The structure diagram of the 2D strain and pressure sensors based on 2D graphene layers structure before the strain and pressure. (b) The structure diagram of the 2D strain and pressure sensors based on 2D graphene layers structure after the strain and pressure. (c) The fabrication process of a 2D structure pressure sensor and its representations. (d) The sensitivity and linearity of this pressure sensor. (e) The response time and hysteresis of this pressure sensor. (f) The fabrication process of a 2D structure pressure sensor and its representations. (g) The sensitivity and linearity of this pressure sensor (h) The response time and hysteresis of this pressure sensor. 


\subsection{Three Dimensional}

Herein, the 3D structure refers to the porous structure and graphene as the main sensing material. The methods for preparing the 3D structure graphene-based strain and pressure sensors are various, such as skeleton erosion and freeze drying. In general, the 3D graphene structure has an internal loose porous structure, which makes it more compressible. The typical structural characterizations of 3D structure strain and pressure sensors are shown in Figure 7a,b. The 3D graphene sponge structure is loose before the strain and pressure, as shown in Figure 7a. In the loading state, the 3D graphene sponge structure becomes shriveled (Figure 7b) [169-172].

Recently, a 3D structure graphene-based strain and pressure sensor was prepared by Zhu et al. by using a neoteric method [142]. This sensor is fabricated by a novel material named as the 3D bubble-derived graphene-based porous material which shows ultrahigh sensitivity, magnificent linearity, and great hysteresis. The above superiorities make it suitable for use in vibration testing and health monitoring. The preparation process of bubble-derived graphene foams (BGFs) was demonstrated in Figure 7c, including the bubbling and ice templating steps. The optic image shows the in-kind shooting of the BGFs. The SEM image shows the porous structure inside the BGFs. As shown in Figure 7d, this 3D structure graphene-based strain and pressure sensor exhibits good linearity over different strain ranges. This phenomenon is due to the different degrees of tearing and fracture under stresses in the internal structure of three-dimensional graphene. This 3D structure graphene-based strain and pressure sensor is also able to test subtle vibration, as shown in Figure 7e.

In another representative case, a novel graphene-based strain and pressure sensor was prepared by dip-coating a polyimide foam template followed by chemical reduction and thermal reduction [153]. This 3D structure graphene-based strain and pressure sensor displays high sensitivity and good linearity, which can be used in health monitoring and human motion detection. The fabrication processes of the sensor are exhibited in Figure $7 \mathrm{f}$ including three main steps. The optic image shows the size can be adjusted. The SEM image shows the inside porous structure. By regulating the density and size of the sensing materials, the internal pore size of the three-dimensional graphene foam can be controlled. As shown in Figure 7g, this 3D structure graphene-based strain and pressure sensor exhibits good linearity over different strain ranges owing to the 3D structure. Figure $7 \mathrm{~h}$ shows high sensitivity up to $0.36 \mathrm{kPa}^{-1}$ in the range of $0-4 \mathrm{kPa}$ under pressure, which demonstrates this $3 \mathrm{D}$ structure graphene-based strain and pressure sensor can both respond to pressure and tension.

The 3D structure is an important part of graphene-based pressure and strain sensors which can be mass produced in large quantities. The graphene 3D structure has both flexible and compressible and good mechanical repeatability of graphene. The 3D structure is a newly-developing form of graphene-based pressure and strain sensors, which also can be used in all transduction methods. The 3D structure graphene-based pressure and strain sensors can be pressured or stretched in all directions in an effective three-dimensional space. It can detect a large or tiny force and has negligible hysteresis, favorable linearity, and ultrahigh dynamic sensitivity. The 3D structure graphene-based pressure and strain sensors have great developing potential in the next decade. 
a

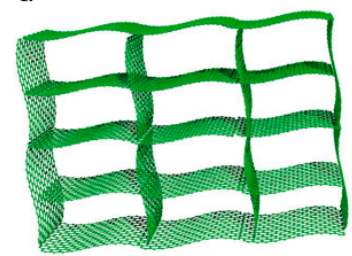

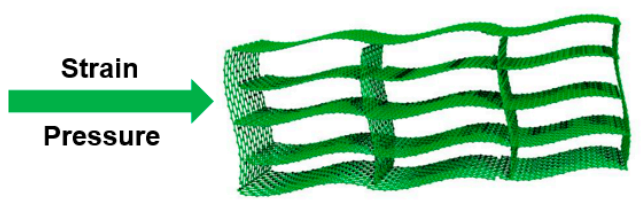
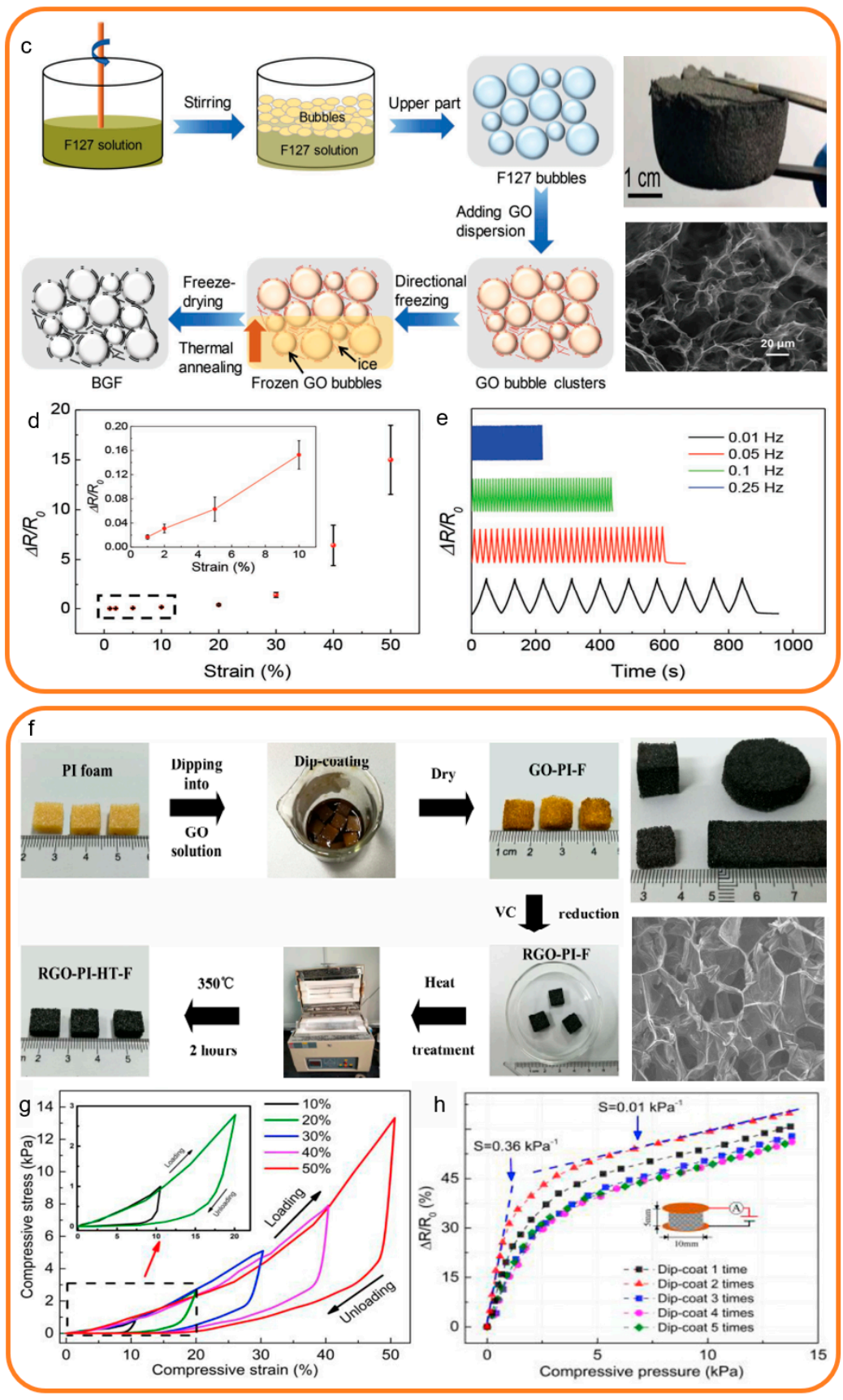

Figure 7. Fabrication processes and structural characterization of 3D structure strain and pressure sensors [142,153]. Copyright 2017, Wiley; Copyright 2018, Elsevier. (a) The structure diagram of the $3 \mathrm{D}$ strain and pressure sensors based on 3D graphene sponge structure before the strain and pressure. (b) The structure diagram of the 3D strain and pressure sensors based on 3D graphene sponge structure after the strain and pressure. (c) The fabrication process of a 3D structure strain and pressure sensor and its representations. (d) The sensitivity and linearity of this strain and pressure sensor. (e) The repeatability and hysteresis of this strain and pressure sensor. (f) The fabrication process of a 3D structure strain and pressure sensor and its representations. (g) The linearity and hysteresis of this strain and pressure sensor. (h) The sensitivity and hysteresis of this pressure sensor. 


\section{Recent Development and Applications of Pressure Sensors}

\subsection{Wearable Devices in the Biomedical Field}

Nowadays, developing wearable devices have drawn tremendous attention in improving health awareness of people. Compared with traditional medical diagnosis, E-skins possess the ability of human motion detection and health parameter collectivity and real-time monitoring. These detected signs can be broadly classified into the inner physiological signal, such as pulse and heart rate, along with the external motion and sound signals like gesture, gait state, and facial expressions [173-176]. Graphene-based sensors show great sensibility in pressure and strain detection, which have provided potential in remote medical diagnosis and in improvement of the bionic machine [177,178].

The physiological signals like pulse and heart rate ought to be recorded with high-precision. Thus, detectability in the low-pressure region and low gauge factors and high sensitivity are essential to the reliable detection of the subtle pulse pressure located variously in the human body, mainly in the radial artery. Gong and co-workers proposed an efficient, low-cost, and ultrathin graphene-based strain sensor with high stretchability and sensitivity [179]. This sensor exhibits GF up to 9.9, stretchability reaches up to $350 \%$, rapid response time about $22 \mathrm{~ms}$, and repeatability greater than 5000 cycles. This graphene-based strain sensor has been applied in human motion detection, which can read radial artery pulse in real-time. In the experiment, the wrist pulses can be measured accurately under ordinary conditions $\left(\approx 66\right.$ beats $\left.\mathrm{min}^{-1}\right)$, as demonstrated in Figure $8 \mathrm{c}$. The same as with a typical radial artery pulse waveform, the curve obtained has two clearly distinguishable peaks, proving the high sensitivity of strain sensors. In light of the radial artery, the pulse wave originates from cardiovascular activity. A close association can be perceived between heart rate and pulse.

Shen and co-workers demonstrated a stable and highly sensitive graphene-based pressure sensor can be applied in human motion detection [180]. The pressure signals sensitivity up to $31.6 \mathrm{kPa}^{-1}$ can be effectively and independently detected in this sensor, which makes it become a simply integrated sensor array with outstanding properties. As shown in the Figure 8d, the sensor records the current signal generated by the undulation of the chest during normal and exercise conditions within $6 \mathrm{~s}$, which can realize the function of monitoring heartbeat signal in real time.

In the case of external motion and sound detection, regular monitoring of these signals is probably an efficient method to supervise the human kinematic state, which puts forward the requirements for sensitivity and detection range. Ren and co-workers proposed a highly sensitive and integrable graphene-based pressure sensor to detect dynamic gait motion [181]. This sensor has ultrahigh sensitivity up to $25.1 \mathrm{kPa}^{-1}$ in a linearity range of $0-2.6 \mathrm{kPa}$, which demonstrates the ability to detect real-time human motion. Three pressure sensors were immobilized on the calcaneus, first metatarsal, and fifth metatarsal to monitor dynamic foot pressure on human skin. As shown in Figure 8e, this sensor can distinguish the neutral gait, supination gait, and pronation gait by monitoring changes in plantar pressure. Except for gait state, gesture and facial expressions are also required to be detected precisely, because of the relevant multiple joints of a single gesture and a large number of muscles on the face. It is worth mentioning the fist-palm salute, a specific gesture. To detect a gesture like that, Gong and co-workers integrated graphene-based strain sensors with existing clothing. As shown in Figure $8 \mathrm{f}$, five strip sensors are stitched onto the finger surface of the glove to detect the movement of each finger, and the sensor assemblies were shown to have quick responses to finger motion. They also applied the sensors to detect facial expressions. Illustrated in Figure 8b, human facial movement can be clearly detected in a highly reproducible manner with a high signal to noise ratio. Another exigent function of e-skin is the identification of sound. The complex motion of the skin extending down a person's throat while saying "Hello" can be reliably identified repeatable. As shown in Figure 8a, the two syllables of the word "Hello" correspond to the two small peaks in the output curve.

All in all, graphene-based strain and pressure sensors exhibit outstanding behavior and great potential for human motion detection and health monitoring, both for physiological and physical 
aspects. With improvement to the properties of the sensor, more accurate health monitoring and motion detection can be achieved [182-184].

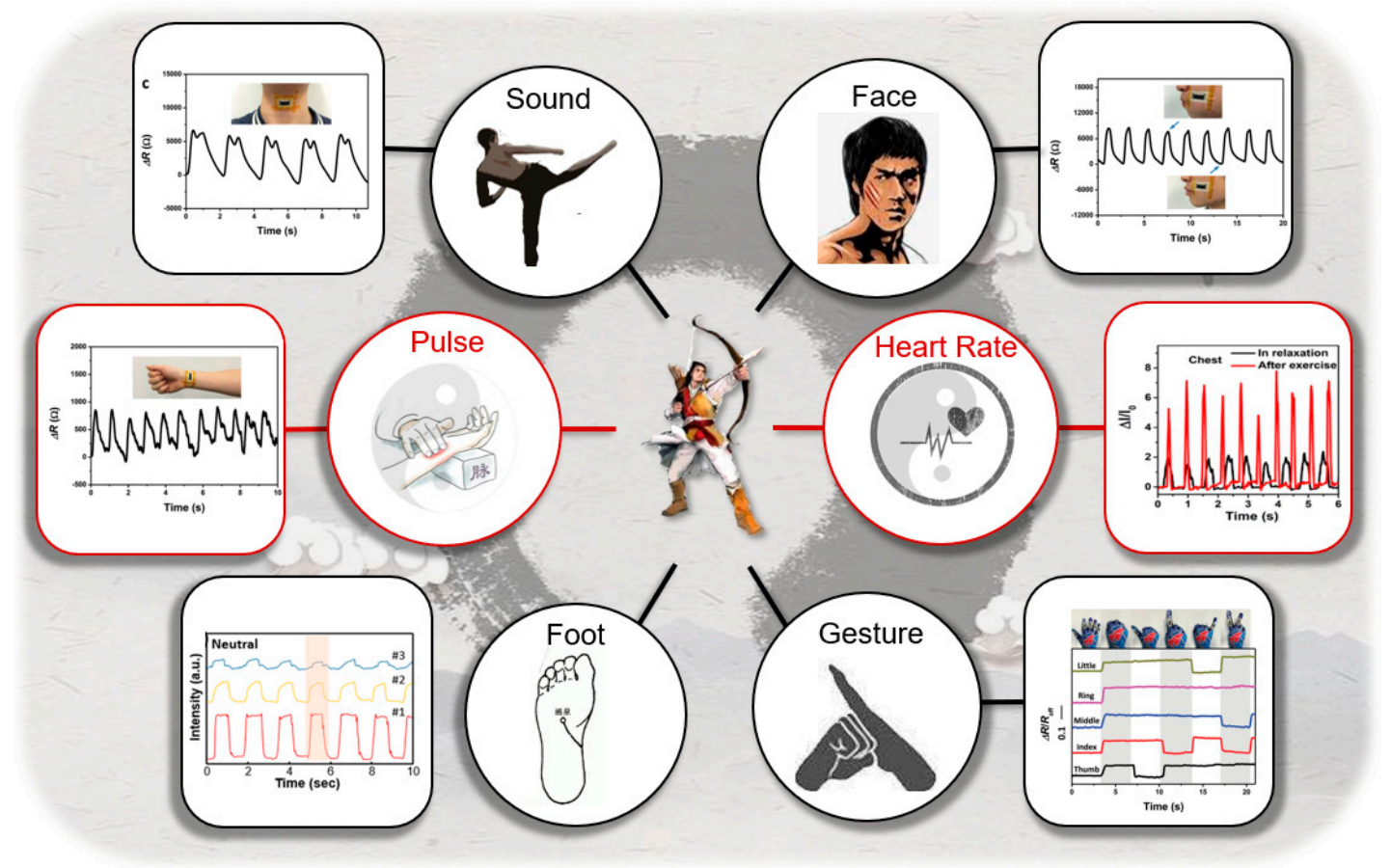

Figure 8. Monitoring in real-time of the graphene-based strain and pressure sensor for human motion detection [179-181]. The insets figures source from [185-192]. Copyright 2015, Wiley; Copyright 2017, Nature Publishing Group; Copyright 2018, American Chemical Society. (a) A graphene-based strain sensor applied to detect throat movement on human skin. (b) A graphene-based strain sensor applied to detect cheek movement on human skin. (c) A graphene-based strain sensor applied to detect wrist pulse on human skin. (d) A graphene-based pressure sensor applied to detect chest pulse on human skin. (e) A graphene-based pressure sensor applied to detect foot pressure on human skin. (f) A graphene-based strain sensor applied to distinguish six different hand positions.

\subsection{From Smart Sensors to Potential Artificial Intelligence Sensors}

In 1950, Alan Turing put forward the famous Turing test in "Can the machine think?" and "Computers and Intelligence". Since then, the academic community has started to discuss the issue of machine thinking. The Dartmouth meeting in 1956 marked the birth of the concept of "artificial intelligence". At present, artificial intelligence is gradually entering the commercial application stage and the critical point of the outbreak is being ushered in. Artificial intelligence is fully entering and reshaping human production and living space. From intelligent robots, smart homes to unmanned vehicles and unmanned factories, artificial intelligence technology is being widely used in various fields of social life and production, changing or even subverting our traditional cognition to the future of agriculture, manufacturing, and law enforcement [193]. The rapid development of artificial intelligence has had a great impact on working forms such as journalism, transportation, medicine, and sports [78]. With the integration of informationalization and industrialization, the boom of intelligence industries represented by robotics, mechatronics, automation, and human-machine interaction has become an important symbol of contemporary technological innovation $[75,194]$. In this section, we intend to use the studies of smart devices and artificial intelligence to point out that flexible sensors have great potential applications of artificial intelligence in the future.

Wang et al. presented a skin-inspired highly stretchable and conformable matrix network (SCMN) which expanded the application of wearable devices in the field of artificial intelligence [195]. The SCMN has multiple functions including detecting strain, pressure, temperature, light, humidity, 
magnetic field, and proximity. Figure 9a shows the real-time detection of pressure distribution and temperature distribution in the array. Figure 9a demonstrates its use in real-time spatial pressure mapping and temperature estimation. The spatial pressure mapping is implemented before and after the $300 \%$ expansion, which indicates that the SCMN is used to identify the location of the pressure load and estimate the size of the loaded object even when the network is stretched and expanded. In addition, this feature can be applied not only to determine the detection range, but also to define the detection area of other external stimuli. By adjusting the sensory nodes of the SCMN, it can be used for multi-function detection, which can be applied to human skin wearable devices in various test environments. Combined with artificial intelligence, the SCMN has a wider range of applications in human-machine interfaces, health monitoring technology, and biomimetic devices.

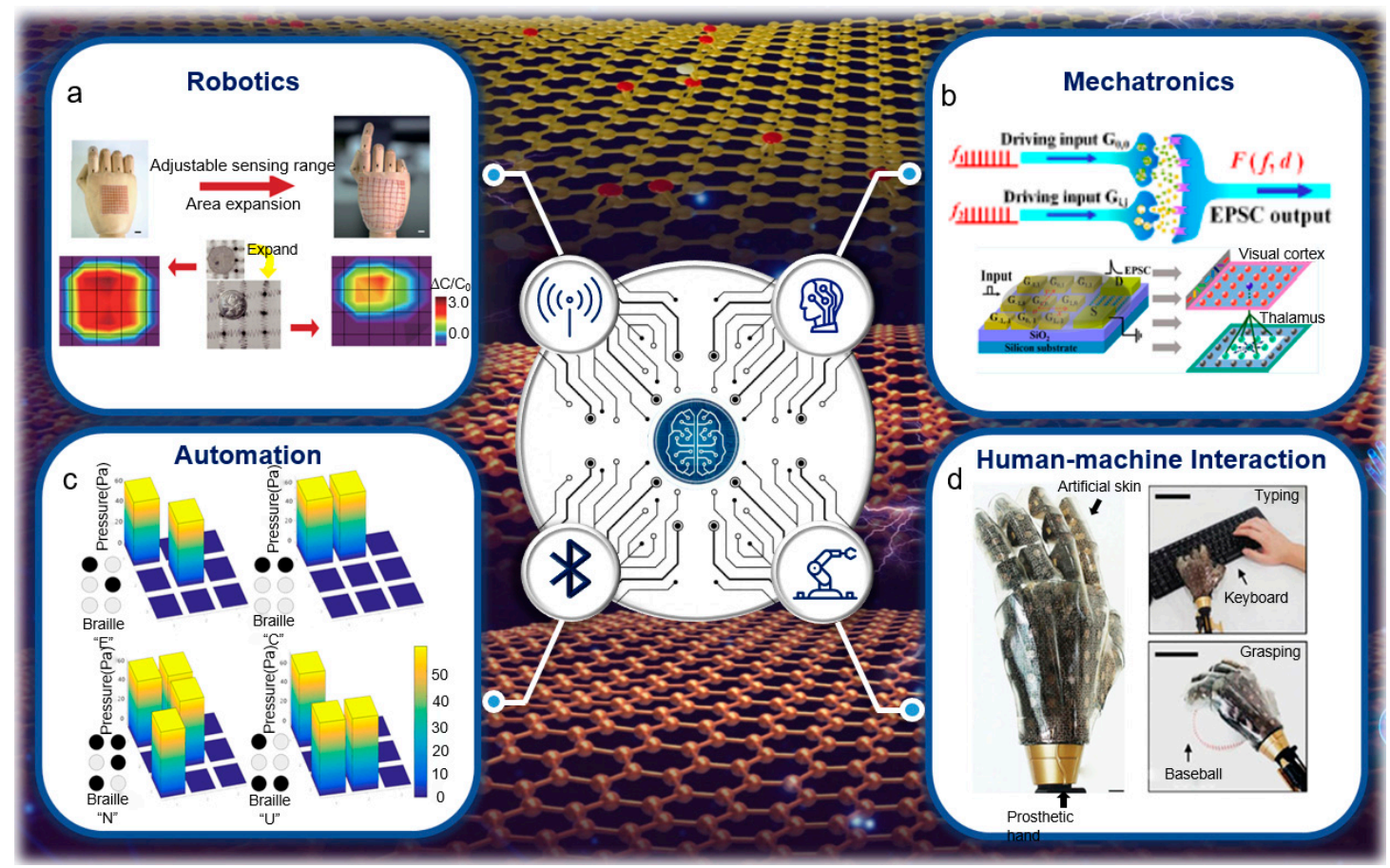

Figure 9. (a) A smart electronic skin on a hand, showing robotics [195]. Copyright 2018, Nature Publishing Group. (b) Mechatronics in artificial intelligence [196]. Copyright 2018, American Chemical Society. (c) Interaction demonstration of smart recognition of the Braille diagram. The Braille diagram is shown on the left corner. Pressure distribution of braille ' $\mathrm{E}^{\prime}{ }^{\prime} \mathrm{C}^{\prime}{ }^{\mathrm{N}} \mathrm{N}^{\prime}$ ' $\mathrm{U}$ ' of the Gr-GO heterostructure film pressure sensor array is shown on the right. The pressure array wirelessly communicates with external devices via Bluetooth. (d) A smart electronic prosthetic hand, which can be used in human-machine interaction [197]. Copyright 2014, Nature Publishing Group.

Wan et al. purposed a two-dimensional electrical double-layer transistor that successfully simulates basic neuromorphic behaviors such as excitatory postsynaptic currents and paired-pulse boosting [196]. The artificial vision neural network system was experimentally verified in these devices, which has great application potential in artificial intelligence and neuronal morphology. Figure 9b shows a simplified schematic of a vision system showing a clear three-layer abstract feedforward mode. The retina is the first layer and is responsible for receiving input. The thalamus is the second layer, a place where there is a one-to-one mapping between the retina and thalamic LGN cells. The visual cortex is the third layer, which is a place to create a many-to-one mapping from the second layer of cells to the third layer of cells. In general, this study indicates the future development of biomimetic nanotechnology.

Recently, our group proposed an ultrasensitive graphene heterostructure pressure sensor, which has not been published yet. Beyond the sensitivity of human skin and muscle, this graphene 
heterostructure pressure sensor has a pressure sensitivity of $5.64 \mathrm{kPa}^{-1}$ and a simultaneous response frequency of at $10 \mathrm{kHz}$. We demonstrate that such multiple functional flexible arrays could be applied to automation with advanced artificial perception. For the interaction demonstration, an artificial recognition of the braille diagram is shown in Figure 9c. The spatial pressure distribution of braille ' $E$ ' ' $\mathrm{C}^{\prime}{ }^{\mathrm{N}}$ ' ' $\mathrm{U}$ ' exhibits that the pressure sensor could assist the blind to communicate with normal people. The pressure array wirelessly communicates with external portable devices via Bluetooth.

Kim et al. demonstrated a stretchable array of multi-kinetic smart prosthetic skin, which can perform multi-function measurements such as strain, pressure, humidity, and temperature [197]. This range of retractable sensors and actuators can respond to external stimuli and promote highly localized mechanical and thermal skin sensing, which provides a new direction for the artificial perception of prosthetic skin. Figure $9 \mathrm{~d}$ shows an image of an artificial skin with integrated electronics laminated on a fake watch face. The artificial skin surface of the prosthesis is highly compliant and mechanically coupled to the curved surface of the prosthesis. The resistance changes in response to keyboard tapping and catching are monitored to explore the performance of the pressure response. The pressure sensor shows a fast and reliable response to external stimuli in both cases, which can be used in future artificial perception prosthetics.

In fact, there are still many challenges in implementing artificial intelligence applications for graphene-based strain and pressure sensors. For instance, how to record a large amount of measurement data and utilize them with artificial intelligence such as deep learning is a key to the application of graphene-based strain and pressure sensors. How to choose the appropriate model algorithm to calculate the parameters is also a difficult point. Furthermore, there are a handful of applications of graphene-based strain and pressure sensors in use, and we need to consider how to appropriately combine the graphene-based strain and pressure sensors with artificial intelligence.

\section{Conclusions and Perspectives}

Due to the magnificent properties including the mechanical, heat resisting, electrical conductivity, and flexibility of graphene, there is currently enormous research into graphene-based mechanical sensors. Graphene-based strain and pressure sensors are widely used in various emerging fields such as device system integration, health monitoring, human motion detection, human-machine interaction, and artificial perception. It is necessary to develop graphene-based strain and pressure sensors to discover potential applications especially in the prevailing trend of artificial intelligence.

In this review, we comprehensively describe ultramodern progress in graphene-based strain and pressure sensors including the sensing mechanism of diverse functional sensors, the main parameters of graphene-based strain and pressure sensors, graphene-based strain and pressure sensors in different dimensionality structures, as well as the potential applications of graphene-based strain and pressure sensors. A mass of publications and reports on the subject of graphene-based strain and pressure sensors demonstrate the urgent demands for various applications in the future.

Although tremendous progress has been achieved during the last decade in graphene-based strain and pressure sensors, there are also enormous challenges such as the negligible but present hysteresis, the balance between high sensitivity and large detection range, the high-frequency vibration test, and biological degradability which remain to be overcome. The large-area device system integration is also a challengeable project. Nowadays, sensor applications in emerging fields have become more and more miniaturized, integrated, and arrayed. This is an inevitable trend in the development of technology, which requires research to further combine sensors with integrated circuits. Additionally, although abundant ultra-sensitive sensors have been reported, novel materials and new-type sensing mechanisms still should be continuously optimized to meet the increasingly demanding application requirements. Moreover, emerging medical technologies such as real-time human health monitoring, prosthetic technology, and clinical medicine are urgently needed for artificial intelligence sensors for health monitoring. With the further development of information transmission technology, future mechanical sensors can be more intelligently controlled in different external environments, which 
are closer to real human skin functions. In the future, most of the mechanical sensors will have to face harsh operating conditions, which require high stability, environmental interference, and adaptive, self-compensating adjustment capabilities. At the same time, in order to ensure that electronic components and modules can achieve large-scale production, the cost also needs to be reduced. We need to improve performance in terms of both technology and cost. Overall, graphene-based strain and pressure sensors have a bright research potential and wide applicability.

Author Contributions: X.W. and Z.L. conceived, designed, wrote, and edited the review. X.H., X.T., C.L., H.X., Q.L. (Quanling Li) and Q.L. (Qianhao Li), modified and revised the review. All authors were involved in writing the review and editing of the paper.

Funding: This work was supported by the NSFC under Grant Nos. 61574060, Projects of Science and Technology Commission of Shanghai Municipality Grant Nos. 15JC1401800 and 14DZ2260800, the Program for Professor of Special Appointment (Eastern Scholar), and Shanghai Rising-Star Program (17QA1401400), and the Fundamental Research Funds for the Central Universities.

Acknowledgments: The authors are grateful to the valuable comments from anonymous referees.

Conflicts of Interest: The authors declare no conflict of interest.

\section{References}

1. Bingger, P.; Woias, P. Highly flexible capacitive strain gauge for continuous long-term blood pressure monitoring. Biomed. Microdevices 2012, 14, 573-581. [CrossRef]

2. Caneva, S.; Gehring, P.; Garcia-Suarez, V.M.; Garcia-Fuente, A.; Stefani, D.; Olavarria-Contreras, I.J.; Ferrer, J.; Dekker, C.; van der Zant, H.S.J. Mechanically controlled quantum interference in graphene break junctions. Nat. Nanotechnol. 2018. [CrossRef] [PubMed]

3. Lou, Z.; Li; Wang, L.; Shen, G. Recent Progress of Self-Powered Sensing Systems for Wearable Electronics. Small 2017, 13. [CrossRef]

4. Mannsfeld, S.C.; Tee, B.C.; Stoltenberg, R.M.; Chen, C.V.; Barman, S.; Muir, B.V.; Sokolov, A.N.; Reese, C.; Bao, Z. Highly sensitive flexible pressure sensors with microstructured rubber dielectric layers. Nat. Mater. 2010, 9, 859-864. [CrossRef]

5. Wang, X.; Gu, Y.; Xiong, Z.; Cui, Z.; Zhang, T. Electronic skin: Silk-molded flexible, ultrasensitive, and highly stable electronic skin for monitoring human physiological signals (adv. Mater. 9/2014). Adv. Mater. 2014, 26, 1309. [CrossRef]

6. Wang, C.; Wu, X.; Ma, Y.; Mu, G.; Li, Y.; Chen, L.; Xu, H.; Zhang, Y.; Yang, J.; Tang, X. Metallic few-layered VSe2 nanosheets: High two-dimensional conductivity for flexible in-plane solid-state supercapacitor. J. Mater. Chem. 2018, 6, 8299-8306. [CrossRef]

7. Wu, X.; Luo, C.; Hao, P.; Sun, T.; Wang, R.; Wang, C.; Hu, Z.; Li, Y.; Zhang, J.; Bersuker, G. Probing and Manipulating the Interfacial Defects of InGaAs Dual-Layer Metal Oxides at the Atomic Scale. Adv. Mater. 2018, 30, 1703025. [CrossRef]

8. Wu, X.; Mei, S.; Bosman, M.; Raghavan, N.; Zhang, X.; Cha, D.; Li, K.; Pey, K.L. Evolution of Filament Formation in $\mathrm{Ni} / \mathrm{HfO}_{2} / \mathrm{SiO}_{\mathrm{x}} / \mathrm{Si}$-Based RRAM Devices. Adv. Electron. Mater. 2016, 1, 1500130. [CrossRef]

9. Wu, X.; Pey, K.L.; Zhang, G.; Bai, P.; Li, X.; Liu, W.H.; Raghavan, N. Electrode material dependent breakdown and recovery in advanced high-k gate stacks. Appl. Phys. Lett. 2010, 96, 327. [CrossRef]

10. Wu, X.; Yu, K.; Cha, D.; Bosman, M.; Raghavan, N.; Zhang, X.; Li, K.; Liu, Q.; Sun, L.; Pey, K. Atomic Scale Modulation of Self-Rectifying Resistive Switching by Interfacial Defects. Adv. Sci. 2018, 5, 1800096. [CrossRef] [PubMed]

11. Zhu, Y.B.; Zheng, K.; Wu, X.; Ang, L.K. Enhanced stability of filament-type resistive switching by interface engineering. Sci. Rep. 2017, 7, 43664. [CrossRef]

12. Fang, L.; Hejun, X.; Xing, W.; Chaolun, W.; Chen, L.; Jian, Z. Raman spectroscopy characterization of two-dimensional materials. Chin. Phys. B 2018, 27, 037802.

13. Stoppa, M.; Chiolerio, A. Wearable electronics and smart textiles: A critical review. Sensors 2014, 14, 11957-11992. [CrossRef] [PubMed]

14. Cataldi, P.; Ceseracciu, L.; Athanassiou, A.; Bayer, I.S. Healable Cotton-Graphene Nanocomposite Conductor for Wearable Electronics. ACS Appl. Mater. Interfaces 2017, 9, 13825-13830. [CrossRef] [PubMed] 
15. Das, T.; Sharma, B.K.; Katiyar, A.K.; Ahn, J.-H. Graphene-based flexible and wearable electronics. J. Semicond. 2018, 39, 011007. [CrossRef]

16. He, J.; Nuzzo, R.G.; Rogers, J.A. Inorganic Materials and Assembly Techniques for Flexible and Stretchable Electronics. Proc. IEEE 2015, 103, 619-632. [CrossRef]

17. Oh, J.Y.; Rondeau-Gagné, S.; Chiu, Y.C.; Chortos, A.; Lissel, F.; Wang, G.N.; Schroeder, B.C.; Kurosawa, T.; Lopez, J.; Katsumata, T. Intrinsically stretchable and healable semiconducting polymer for organic transistors. Nature 2016, 539, 411. [CrossRef]

18. Chen, X. Making Electrodes Stretchable. Small Methods 2017, 1, 1600029. [CrossRef]

19. Lu, N.; Lu, C.; Yang, S.; Rogers, J. Highly Sensitive Skin-Mountable Strain Gauges Based Entirely on Elastomers. Adv. Funct. Mater. 2012, 22, 4044-4050. [CrossRef]

20. Morteza, A.; Aekachan, P.; Sangjun, L.; Seunghwa, R.; Inkyu, P. Highly stretchable and sensitive strain sensor based on silver nanowire-elastomer nanocomposite. ACS Nano 2014, 8, 5154-5163.

21. Tang, W.; Yan, T.; Ping, J.; Wu, J.; Ying, Y. Rapid Fabrication of Flexible and Stretchable Strain Sensor by Chitosan-Based Water Ink for Plants Growth Monitoring. Adv. Mater. Technol. 2017, 2, 1700021. [CrossRef]

22. Kang, S.; Lee, J.; Lee, S.; Kim, S.G.; Kim, J.K.; Algadi, H.; Al-Sayari, S.; Kim, D.E.; Kim, D.E.; Lee, T. Highly Sensitive Pressure Sensor Based on Bioinspired Porous Structure for Real-Time Tactile Sensing. Adv. Electron. Mater. 2016, 2, 1600356. [CrossRef]

23. Boutry, C.M.; Nguyen, A.; Lawal, Q.O.; Chortos, A.; Rondeau-Gagné, S.; Bao, Z. Pressure Sensors: A Sensitive and Biodegradable Pressure Sensor Array for Cardiovascular Monitoring (Adv. Mater. 43/2015). Adv. Mater. 2016, 27, 6954-6961. [CrossRef] [PubMed]

24. Changhyun, P.; Ja Hoon, K.; Amanda, N.; Caves, J.M.; Myung-Gil, K.; Alex, C.; Kwanpyo, K.; Wang, P.J.; Jeffrey, B.-H.; et al. Highly skin-conformal microhairy sensor for pulse signal amplification. Adv. Mater. 2015, 27, 634-640.

25. Mcevoy, M.A.; Correll, N. Materials science. Materials that couple sensing, actuation, computation, and communication. Science 2015, 347, 1261689. [CrossRef] [PubMed]

26. Pang, C.; Lee, C.; Suh, K.Y. Recent advances in flexible sensors for wearable and implantable devices. J. Appl. Polym. Sci. 2013, 130, 1429-1441. [CrossRef]

27. Zhao, S.; Zhu, R. Electronic Skin with Multifunction Sensors Based on Thermosensation. Adv. Mater. 2017, 29, 1606151. [CrossRef] [PubMed]

28. Steve, P.; Hyunjin, K.; Michael, V.; Sangmo, C.; Hyeok, K.; Ja Hoon, K.; Taeho Roy, K.; Sanghyo, L.; Gregory, S.; Hyuk, C. Stretchable energy-harvesting tactile electronic skin capable of differentiating multiple mechanical stimuli modes. Adv. Mater. 2014, 26, 7324-7332.

29. Luo, C.; Wang, C.; Wu, X.; Zhang, J.; Chu, J. In Situ Transmission Electron Microscopy Characterization and Manipulation of Two-Dimensional Layered Materials beyond Graphene. Small 2017, 13, 1604259. [CrossRef]

30. Xu, H.; Wu, X.; Li, X.; Luo, C.; Liang, F.; Orignac, E.; Zhang, J.; Chu, J. Properties of graphene-metal contacts probed by Raman spectroscopy. Carbon 2018, 127, 491-497. [CrossRef]

31. Li, X.; Zhang, R.; Yu, W.; Wang, K.; Wei, J.; Wu, D.; Cao, A.; Li, Z.; Cheng, Y.; Zheng, Q.; et al. Stretchable and highly sensitive graphene-on-polymer strain sensors. Sci. Rep. 2012, 2, 870. [CrossRef]

32. Cataldi, P.; Athanassiou, A.; Bayer, I. Graphene Nanoplatelets-Based Advanced Materials and Recent Progress in Sustainable Applications. Appl. Sci. 2018, 8, 1438. [CrossRef]

33. Wang, B.; Lee, B.K.; Kwak, M.J.; Lee, D.W. Graphene/polydimethylsiloxane nanocomposite strain sensor. Rev. Sci. Instrum. 2013, 84, 105005. [CrossRef]

34. Chen, Z.; Wang, Z.; Li, X.; Lin, Y.; Luo, N.; Long, M.; Zhao, N.; Xu, J.B. Flexible Piezoelectric-Induced Pressure Sensors for Static Measurements Based on Nanowires/Graphene Heterostructures. ACS Nano 2017, 11, 4507-4513. [CrossRef]

35. Sun, Q.; Seung, W.; Kim, B.J.; Seo, S.; Kim, S.W.; Cho, J.H. Active Matrix Electronic Skin Strain Sensor Based on Piezopotential-Powered Graphene Transistors. Adv. Mater. 2015, 27, 3411-3417. [CrossRef]

36. Dagdeviren, C.; Shi, Y.; Joe, P.; Ghaffari, R.; Balooch, G.; Usgaonkar, K.; Gur, O.; Tran, P.L.; Crosby, J.R.; Meyer, M.; et al. Conformal piezoelectric systems for clinical and experimental characterization of soft tissue biomechanics. Nat. Mater. 2015, 14, 728-736. [CrossRef]

37. Gao, W.; Emaminejad, S.; Nyein, H.Y.Y.; Challa, S.; Chen, K.; Peck, A.; Fahad, H.M.; Ota, H.; Shiraki, H.; Kiriya, D.; et al. Fully integrated wearable sensor arrays for multiplexed in situ perspiration analysis. Nature 2016, 529, 509-514. [CrossRef] 
38. Hattori, Y.; Falgout, L.; Lee, W.; Jung, S.Y.; Poon, E.; Lee, J.W.; Na, I.; Geisler, A.; Sadhwani, D.; Zhang, Y.; et al. Multifunctional skin-like electronics for quantitative, clinical monitoring of cutaneous wound healing. Adv. Mater. 2014, 3, 1597-1607. [CrossRef]

39. Kaltenbrunner, M.; Sekitani, T.; Reeder, J.; Yokota, T.; Kuribara, K.; Tokuhara, T.; Drack, M.; Schwodiauer, R.; Graz, I.; Bauer-Gogonea, S.; et al. An ultra-lightweight design for imperceptible plastic electronics. Nature 2013, 499, 458-463. [CrossRef]

40. Kim, D.H.; Lu, N.; Ma, R.; Kim, Y.S.; Kim, R.H.; Wang, S.; Wu, J.; Won, S.M.; Tao, H.; Islam, A.; et al. Epidermal electronics. Science 2011, 333, 838-843. [CrossRef]

41. Lee, S.M.; Byeon, H.J.; Lee, J.H.; Baek, D.H.; Lee, K.H.; Hong, J.S.; Lee, S.H. Self-adhesive epidermal carbon nanotube electronics for tether-free long-term continuous recording of biosignals. Sci. Rep. 2014, 4, 6074. [CrossRef] [PubMed]

42. Mikkelsen, K.B.; Kappel, S.L.; Mandic, D.P.; Kidmose, P. EEG Recorded from the Ear: Characterizing the Ear-EEG Method. Front. Neurosci. 2015, 9, 438. [CrossRef] [PubMed]

43. Pang, C.; Lee, G.Y.; Kim, T.I.; Kim, S.M.; Kim, H.N.; Ahn, S.H.; Suh, K.Y. A flexible and highly sensitive strain-gauge sensor using reversible interlocking of nanofibres. Nat. Mater. 2012, 11, 795-801. [CrossRef] [PubMed]

44. Park, S.I.; Xiong, Y.; Kim, R.H.; Elvikis, P.; Meitl, M.; Kim, D.H.; Wu, J.; Yoon, J.; Yu, C.J.; Liu, Z.; et al. Printed assemblies of inorganic light-emitting diodes for deformable and semitransparent displays. Science 2009, 325, 977-981. [CrossRef] [PubMed]

45. Schwartz, G.; Tee, B.C.; Mei, J.; Appleton, A.L.; Kim, D.H.; Wang, H.; Bao, Z. Flexible polymer transistors with high pressure sensitivity for application in electronic skin and health monitoring. Nat. Commun. 2013, 4, 1859. [CrossRef] [PubMed]

46. Valentine, A.D.; Busbee, T.A.; Boley, J.W.; Raney, J.R.; Chortos, A.; Kotikian, A.; Berrigan, J.D.; Durstock, M.F.; Lewis, J.A. Hybrid 3D Printing of Soft Electronics. Adv. Mater. 2017, 29, 1703817. [CrossRef] [PubMed]

47. Webb, R.C.; Bonifas, A.P.; Behnaz, A.; Zhang, Y.; Yu, K.J.; Cheng, H.; Shi, M.; Bian, Z.; Liu, Z.; Kim, Y.S.; et al. Ultrathin conformal devices for precise and continuous thermal characterization of human skin. Nat. Mater. 2013, 12, 938-944. [CrossRef]

48. Yeo, W.H.; Kim, Y.S.; Lee, J.; Ameen, A.; Shi, L.; Li, M.; Wang, S.; Ma, R.; Jin, S.H.; Kang, Z.; et al. Multifunctional epidermal electronics printed directly onto the skin. Adv. Mater. 2013, 25, 2773-2778. [CrossRef]

49. Koh, A.; Kang, D.; Xue, Y.; Lee, S.; Pielak, R.M.; Kim, J.; Hwang, T.; Min, S.; Banks, A.; Bastien, P.; et al. A soft, wearable microfluidic device for the capture, storage, and colorimetric sensing of sweat. Sci. Transl. Med. 2016, 8, 366ra165. [CrossRef]

50. Huang, X.; Cheng, H.; Chen, K.; Zhang, Y.; Zhang, Y.; Liu, Y.; Zhu, C.; Ouyang, Sh.; Kong, Gi.; Yu, C.; Huang, Y.; Rogers, J.A. Epidermal impedance sensing sheets for precision hydration assessment and spatial mapping. IEEE Trans. Biomed. Eng. 2013, 60, 2848-2857. [CrossRef]

51. Araki, H.; Kim, J.; Zhang, S.; Banks, A.; Crawford, K.E.; Sheng, X.; Gutruf, P.; Shi, Y.; Pielak, R.M.; Rogers, J.A. Materials and Device Designs for an Epidermal UV Colorimetric Dosimeter with Near Field Communication Capabilities. Adv. Funct. Mater. 2016, 27, 1604465. [CrossRef]

52. Yokota, T.; Zalar, P.; Kaltenbrunner, M.; Jinno, H.; Matsuhisa, N.; Kitanosako, H.; Tachibana, Y.; Yukita, W.; Koizumi, M.; Someya, T. Ultraflexible organic photonic skin. Sci. Adv. 2016, 2, e1501856. [CrossRef]

53. Rather, J.A.; Wael, K.D. Fullerene-C 60 sensor for ultra-high sensitive detection of bisphenol-A and its treatment by green technology. Sens. Actuators B Chem. 2013, 176, 110-117. [CrossRef]

54. Mazloum-Ardakani, M.; Khoshroo, A. High performance electrochemical sensor based on fullerene-functionalized carbon nanotubes/ionic liquid: Determination of some catecholamines. Electrochem. Commun. 2014, 42, 9-12. [CrossRef]

55. Dong, Z.; Jiang, C.; Cheng, H.; Zhao, Y.; Shi, G.; Jiang, L.; Qu, L. Facile fabrication of light, flexible and multifunctional graphene fibers. Adv. Mater. 2012, 24, 1856-1861. [CrossRef] [PubMed]

56. Xu, Z.; Gao, C. Graphene fiber: A new trend in carbon fibers. Mater. Today 2015, 18, 480-492. [CrossRef]

57. Jun, M.; Wei, J.; Hoi Lut, H.; Ji Yan, D. High-sensitivity fiber-tip pressure sensor with graphene diaphragm. Opt. Lett. 2012, 37, 2493-2495.

58. Bae, S.H.; Lee, Y.; Sharma, B.K.; Lee, H.J.; Kim, J.H.; Ahn, J.H. Graphene-based transparent strain sensor. Carbon 2013, 51, 236-242. [CrossRef] 
59. Keun Soo, K.; Yue, Z.; Houk, J.; Yoon, L.S.; Jong Min, K.; Kim, K.S.; Jong-Hyun, A.; Philip, K.; Jae-Young, C.; Byung Hee, H. Large-scale pattern growth of graphene films for stretchable transparent electrodes. Nature 2009, 457, 706-710.

60. Lee, C.; Wei, X.; Kysar, J.W.; Hone, J. Measurement of the elastic properties and intrinsic strength of monolayer graphene. Science 2008, 321, 385-388. [CrossRef]

61. Ruiz-Vargas, C.S.; Zhuang, H.L.; Huang, P.Y.; van der Zande, A.M.; Garg, S.; McEuen, P.L.; Muller, D.A.; Hennig, R.G.; Park, J. Softened elastic response and unzipping in chemical vapor deposition graphene membranes. Nano Lett. 2011, 11, 2259-2263. [CrossRef]

62. Zhang, Y.; Huang, Y.; Zhang, T.; Chang, H.; Xiao, P.; Chen, H.; Huang, Z.; Chen, Y. Broadband and tunable high-performance microwave absorption of an ultralight and highly compressible graphene foam. Adv. Mater. 2015, 27, 2049-2053. [CrossRef] [PubMed]

63. Xu, X.; Sun, Z.; Chua, D.H.C.; Pan, L. Novel nitrogen doped graphene sponge with ultrahigh capacitive deionization performance. Sci. Rep. 2015, 5, 11225. [CrossRef]

64. Chen, Z.; Ren, W.; Gao, L.; Liu, B.; Pei, S.; Cheng, H.M. Three-dimensional flexible and conductive interconnected graphene networks grown by chemical vapour deposition. Nat. Mater. 2011, 10, 424-428. [CrossRef] [PubMed]

65. Sha, J.; Li, Y.; Villegas Salvatierra, R.; Wang, T.; Dong, P.; Ji, Y.; Lee, S.K.; Zhang, C.; Zhang, J.; Smith, R.H.; et al. Three-Dimensional Printed Graphene Foams. ACS Nano 2017, 11, 6860-6867. [CrossRef] [PubMed]

66. Woo, S.; Kim, Y.-R.; Chung, T.D.; Piao, Y.; Kim, H. Synthesis of a graphene-carbon nanotube composite and its electrochemical sensing of hydrogen peroxide. Electrochim. Acta 2012, 59, 509-514. [CrossRef]

67. Sun, X.; Sun, H.; Li, H.; Peng, H. Developing polymer composite materials: Carbon nanotubes or graphene? Adv. Mater. 2013, 25, 5153-5176. [CrossRef] [PubMed]

68. Kuang, J.; Dai, Z.; Liu, L.; Yang, Z.; Jin, M.; Zhang, Z. Synergistic effects from graphene and carbon nanotubes endow ordered hierarchical structure foams with a combination of compressibility, super-elasticity and stability and potential application as pressure sensors. Nanoscale 2015, 7, 9252-9260. [CrossRef] [PubMed]

69. Xu, X.; Wang, R.; Nie, P.; Cheng, Y.; Lu, X.; Shi, L.; Sun, J. Copper Nanowire-Based Aerogel with Tunable Pore Structure and Its Application as Flexible Pressure Sensor. ACS Appl. Mater. Interfaces 2017, 9, 14273-14280. [CrossRef] [PubMed]

70. Wang, X.; Liu, Z.; Zhang, T. Flexible Sensing Electronics for Wearable/Attachable Health Monitoring. Small 2017, 13, 1602790. [CrossRef] [PubMed]

71. Yang, T.; Xie, D.; Li, Z.; Zhu, H. Recent advances in wearable tactile sensors: Materials, sensing mechanisms, and device performance. Mater. Sci. Eng. R Rep. 2017, 115, 1-37. [CrossRef]

72. Nassar, J.M.; Mishra, K.; Lau, K.; Aguirre-Pablo, A.A.; Hussain, M.M. Recyclable Nonfunctionalized Paper-Based Ultralow-Cost Wearable Health Monitoring System. Adv. Mater. Technol. 2017, 2, 1600228. [CrossRef]

73. Chi, H.L.; Ma, Y.; Jang, K.I.; Banks, A.; Pan, T.; Feng, X.; Kim, J.S.; Kang, D.; Raj, M.S.; Mcgrane, B.L. Soft Core/Shell Packages for Stretchable Electronics. Adv. Funct. Mater. 2015, 25, 3698-3704.

74. Xi, W.; Yeo, J.C.; Yu, L.; Zhang, S.; Lim, C.T. Ultrathin and Wearable Microtubular Epidermal Sensor for Real-Time Physiological Pulse Monitoring. Adv. Mater. Technol. 2017, 2, 1700016. [CrossRef]

75. Zang, Y.; Zhang, F.; Di, C.A.; Zhu, D. Advances of flexible pressure sensors toward artificial intelligence and health care applications. Mater. Horiz. 2015, 2, 25-59. [CrossRef]

76. Lim, S.; Son, D.; Kim, J.; Lee, Y.B.; Song, J.K.; Choi, S.; Dong, J.L.; Ji, H.K.; Lee, M.; Hyeon, T. Transparent and Stretchable Interactive Human Machine Interface Based on Patterned Graphene Heterostructures. Adv. Funct. Mater. 2015, 25, 375-383. [CrossRef]

77. Lee, S.; Reuveny, A.; Reeder, J.; Lee, S.; Jin, H.; Liu, Q.; Yokota, T.; Sekitani, T.; Isoyama, T.; Abe, Y. A transparent bending-insensitive pressure sensor. Nat. Nanotechnol. 2016, 11, 472-478. [CrossRef] [PubMed]

78. Tao, L.Q.; Tian, H.; Liu, Y.; Ju, Z.Y.; Pang, Y.; Chen, Y.Q.; Wang, D.Y.; Tian, X.G.; Yan, J.C.; Deng, N.Q. An intelligent artificial throat with sound-sensing ability based on laser induced graphene. Nat. Commun. 2017, 8, 14579. [CrossRef] [PubMed]

79. Gong, S.; Schwalb, W.; Wang, Y.; Chen, Y.; Tang, Y.; Si, J.; Shirinzadeh, B.; Cheng, W. A wearable and highly sensitive pressure sensor with ultrathin gold nanowires. Nat. Commun. 2014, 5, 3132. [CrossRef] [PubMed] 
80. Li, C.; Jiang, D.; Liang, H.; Huo, B.; Liu, C.; Yang, W.; Liu, J. Superelastic and Arbitrary-Shaped Graphene Aerogels with Sacrificial Skeleton of Melamine Foam for Varied Applications. Adv. Funct. Mater. 2018, 28, 1704674. [CrossRef]

81. Wu, S.; Ladani, R.B.; Zhang, J.; Ghorbani, K.; Zhang, X.; Mouritz, A.P.; Kinloch, A.J.; Wang, C.H. Strain Sensors with Adjustable Sensitivity by Tailoring the Microstructure of Graphene Aerogel/PDMS Nanocomposites. ACS Appl. Mater. Interfaces 2016, 8, 24853-24861. [CrossRef] [PubMed]

82. Liu, H.; Dong, M.; Huang, W.; Gao, J.; Dai, K.; Guo, J.; Zheng, G.; Liu, C.; Shen, C.; Guo, Z. Lightweight conductive graphene/thermoplastic polyurethane foams with ultrahigh compressibility for piezoresistive sensing. J. Mater. Chem. C 2017, 5, 73-83. [CrossRef]

83. Windmiller, J.R.; Wang, J. Wearable Electrochemical Sensors and Biosensors: A Review. Electroanalysis 2013, 25, 29-46. [CrossRef]

84. Yan, C.; Wang, J.; Kang, W.; Cui, M.; Wang, X.; Foo, C.Y.; Chee, K.J.; Lee, P.S. Highly stretchable piezoresistive graphene-nanocellulose nanopaper for strain sensors. Adv. Mater. 2014, 26, 2022-2027. [CrossRef] [PubMed]

85. Zhu, S.-E.; Krishna Ghatkesar, M.; Zhang, C.; Janssen, G.C.A.M. Graphene based piezoresistive pressure sensor. Appl. Phys. Lett. 2013, 102, 161904. [CrossRef]

86. Yao, H.B.; Ge, J.; Wang, C.F.; Wang, X.; Hu, W.; Zheng, Z.J.; Ni, Y.; Yu, S.H. A flexible and highly pressure-sensitive graphene-polyurethane sponge based on fractured microstructure design. Adv. Mater. 2013, 25, 6692-6698. [CrossRef]

87. Cataldi, P.; Ceseracciu, L.; Marras, S.; Athanassiou, A.; Bayer, I.S. Electrical conductivity enhancement in thermoplastic polyurethane-graphene nanoplatelet composites by stretch-release cycles. Appl. Phys. Lett. 2017, 110, 121904. [CrossRef]

88. Lee, M.S.; Lee, K.; Kim, S.Y.; Lee, H.; Park, J.; Choi, K.H.; Kim, H.K.; Kim, D.G.; Lee, D.Y.; Nam, S.; et al. High-performance, transparent, and stretchable electrodes using graphene-metal nanowire hybrid structures. Nano Lett. 2013, 13, 2814-2821. [CrossRef]

89. Xia, X.H.; Chao, D.L.; Zhang, Y.Q.; Shen, Z.X.; Fan, H.J. Three-dimensional graphene and their integrated electrodes. Nano Today 2014, 9, 785-807. [CrossRef]

90. Jonghwa, P.; Youngoh, L.; Jaehyung, H.; Minjeong, H.; Young-Do, J.; Hyuneui, L.; Sung Youb, K.; Hyunhyub, K. Giant tunneling piezoresistance of composite elastomers with interlocked microdome arrays for ultrasensitive and multimodal electronic skins. ACS Nano 2014, 8, 4689-4697.

91. Pan, L.; Chortos, A.; Yu, G.; Wang, Y.; Isaacson, S.; Allen, R.; Shi, Y.; Dauskardt, R.; Bao, Z. An ultra-sensitive resistive pressure sensor based on hollow-sphere microstructure induced elasticity in conducting polymer film. Nat. Commun. 2014, 5, 3002. [CrossRef] [PubMed]

92. Ruo-Zhou, L.; Anming, H.; Tong, Z.; Oakes, K.D. Direct writing on paper of foldable capacitive touch pads with silver nanowire inks. ACS Appl. Mater. Interfaces 2014, 6, 21721-21729.

93. Woo, S.J.; Kong, J.H.; Kim, D.G.; Kim, J.M. A thin all-elastomeric capacitive pressure sensor array based on micro-contact printed elastic conductors. J. Mater. Chem. C 2014, 2, 4415-4422. [CrossRef]

94. Persano, L.; Dagdeviren, C.; Su, Y.; Zhang, Y.; Girardo, S.; Pisignano, D.; Huang, Y.; Rogers, J.A. High performance piezoelectric devices based on aligned arrays of nanofibers of poly(vinylidenefluorideco-trifluoroethylene). Nat. Commun. 2013, 4, 1633. [CrossRef] [PubMed]

95. Wenzhuo, W.; Xiaonan, W.; Zhong Lin, W. Taxel-addressable matrix of vertical-nanowire piezotronic transistors for active and adaptive tactile imaging. Science 2013, 340, 952-957.

96. Wang, X.; Dong, L.; Zhang, H.; Yu, R.; Pan, C.; Wang, Z.L. Recent Progress in Electronic Skin. Adv. Sci. (Weinh) 2015, 2, 1500169. [CrossRef] [PubMed]

97. Chwee-Lin, C.; Mun-Bo, S.; Byoung-Sun, L.; Sanghun, J.; Dong-Su, K.; Tae-Hyung, K.; Jihyun, B.; Sung Hoon, L.; Kyung-Eun, B.; Jungkyun, I. Highly stretchable resistive pressure sensors using a conductive elastomeric composite on a micropyramid array. Adv. Mater. 2014, 26, 3451-3458.

98. Liu, Y.; Tao, L.-Q.; Wang, D.-Y.; Zhang, T.-Y.; Yang, Y.; Ren, T.-L. Flexible, highly sensitive pressure sensor with a wide range based on graphene-silk network structure. Appl. Phys. Lett. 2017, 110, 123508. [CrossRef]

99. Samad, Y.A.; Li, Y.; Schiffer, A.; Alhassan, S.M.; Liao, K. Graphene foam developed with a novel two-step technique for low and high strains and pressure-sensing applications. Small 2015, 11, 2380-2385. [CrossRef]

100. He, Y.; Li, W.; Yang, G.; Liu, H.; Lu, J.; Zheng, T.; Li, X. A Novel Method for Fabricating Wearable, Piezoresistive, and Pressure Sensors Based on Modified-Graphite/Polyurethane Composite Films. Materials 2017, 10, 684. [CrossRef] 
101. Chen, S.; Jiang, K.; Lou, Z.; Chen, D.; Shen, G. Recent Developments in Graphene-Based Tactile Sensors and E-Skins. Adv. Mater. Technol. 2018, 3, 1700248. [CrossRef]

102. Tsui, M.N.; Islam, M.F. Creep- and fatigue-resistant, rapid piezoresistive responses of elastomeric graphene-coated carbon nanotube aerogels over a wide pressure range. Nanoscale 2016, 9, 1128. [CrossRef] [PubMed]

103. Bae, G.Y.; Pak, S.W.; Kim, D.; Lee, G.; Kim do, H.; Chung, Y.; Cho, K. Linearly and Highly Pressure-Sensitive Electronic Skin Based on a Bioinspired Hierarchical Structural Array. Adv. Mater. 2016, 28, 5300-5306. [CrossRef] [PubMed]

104. Lv, L.; Zhang, P.; Xu, T.; Qu, L. Ultrasensitive Pressure Sensor Based on an Ultralight Sparkling Graphene Block. ACS Appl. Mater. Interfaces 2017, 9, 22885-22892. [CrossRef] [PubMed]

105. Lipomi, D.J.; Vosgueritchian, M.; Tee, B.C.; Hellstrom, S.L.; Lee, J.A.; Fox, C.H.; Bao, Z. Skin-like pressure and strain sensors based on transparent elastic films of carbon nanotubes. Nat. Nanotechnol. 2011, 6, 788-792. [CrossRef] [PubMed]

106. Pan, C.; Dong, L.; Zhu, G.; Niu, S.; Yu, R.; Yang, Q.; Liu, Y.; Wang, Z.L. High-resolution electroluminescent imaging of pressure distribution using a piezoelectric nanowire LED array. Nat. Photonics 2013, 7, 752-758. [CrossRef]

107. Pyo, S.; Choi, J.; Kim, J. Flexible, Transparent, Sensitive, and Crosstalk-Free Capacitive Tactile Sensor Array Based on Graphene Electrodes and Air Dielectric. Adv. Electron. Mater. 2018, 4, 1700427. [CrossRef]

108. Cataldi, P.; Dussoni, S.; Ceseracciu, L.; Maggiali, M.; Natale, L.; Metta, G.; Athanassiou, A.; Bayer, I.S. Carbon Nanofiber versus Graphene-Based Stretchable Capacitive Touch Sensors for Artificial Electronic Skin. Adv. Sci. 2018, 5, 1700587. [CrossRef] [PubMed]

109. Mitrakos, V.; Macintyre, L.; Denison, F.; Hands, P.; Desmulliez, M. Design, Manufacture and Testing of Capacitive Pressure Sensors for Low-Pressure Measurement Ranges. Micromachines 2017, 8, 41. [CrossRef]

110. Nie, B.; Li, R.; Cao, J.; Brandt, J.D.; Pan, T. Flexible transparent iontronic film for interfacial capacitive pressure sensing. Adv. Mater. 2015, 27, 6055-6062. [CrossRef]

111. Wan, S.; Bi, H.; Zhou, Y.; Xie, X.; Su, S.; Yin, K.; Sun, L. Graphene oxide as high-performance dielectric materials for capacitive pressure sensors. Carbon 2017, 114, 209-216. [CrossRef]

112. He, Z.; Chen, W.; Liang, B.; Liu, C.; Yang, L.; Lu, D.; Mo, Z.; Zhu, H.; Tang, Z.; Gui, X. Capacitive Pressure Sensor with High Sensitivity and Fast Response to Dynamic Interaction Based on Graphene and Porous Nylon Networks. ACS Appl. Mater. Interfaces 2018, 10, 12816-12823. [CrossRef]

113. Choi, T.; Hwang, B.U.; Kim, B.Y.; Trung, T.Q.; Nam, Y.H.; Kim, D.N.; Eom, K.; Lee, N.E. Stretchable, Transparent and Stretch-Unresponsive Capacitive Touch Sensor Array with Selectively Patterned Silver Nanowires/Reduced Graphene Oxide Electrodes. ACS Appl. Mater. Interfaces 2017, 9, 18022-18030. [CrossRef] [PubMed]

114. Chen, Y.M.; He, S.M.; Huang, C.H.; Huang, C.C.; Shih, W.P.; Chu, C.L.; Kong, J.; Li, J.; Su, C.Y. Ultra-large suspended graphene as a highly elastic membrane for capacitive pressure sensors. Nanoscale 2016, 8 , 3555-3564. [CrossRef] [PubMed]

115. Ho, D.H.; Sun, Q.; Kim, S.Y.; Han, J.T.; Kim, D.H.; Cho, J.H. Stretchable and Multimodal All Graphene Electronic Skin. Adv. Mater. 2016, 28, 2601-2608. [CrossRef] [PubMed]

116. Tang, Q.; Yang, P. The era of water-enabled electricity generation from graphene. J. Mater. Chem. 2016, 4, 9730-9738. [CrossRef]

117. Zhong Lin, W.; Jinhui, S. Piezoelectric nanogenerators based on zinc oxide nanowire arrays. Science 2006, 312, 242-246.

118. Khan, U.; Kim, T.H.; Ryu, H.; Seung, W.; Kim, S.W. Graphene Tribotronics for Electronic Skin and Touch Screen Applications. Adv. Mater. 2017, 29, 1603544. [CrossRef] [PubMed]

119. Zhong, H.; Xia, J.; Wang, F.; Chen, H.; Wu, H.; Lin, S. Graphene-Piezoelectric Material Heterostructure for Harvesting Energy from Water Flow. Adv. Funct. Mater. 2016, 27, 1604226. [CrossRef]

120. Yogeswaran, N.; Navaraj, W.T.; Gupta, S.; Liu, F.; Vinciguerra, V.; Lorenzelli, L.; Dahiya, R. Piezoelectric graphene field effect transistor pressure sensors for tactile sensing. Appl. Phys. Lett. 2018, 113, 014102. [CrossRef]

121. Plesco, I.; Dragoman, M.; Strobel, J.; Ghimpu, L.; Schütt, F.; Dinescu, A.; Ursaki, V.; Kienle, L.; Adelung, R.; Tiginyanu, I. Flexible pressure sensor based on graphene aerogel microstructures functionalized with CdS nanocrystalline thin film. Superlattices Microstruct. 2018, 117, 418-422. [CrossRef] 
122. Amjadi, M.; Kyung, K.U.; Park, I.; Sitti, M. Stretchable, Skin-Mountable, and Wearable Strain Sensors and Their Potential Applications: A Review. Adv. Funct. Mater. 2016, 26, 1678-1698. [CrossRef]

123. Tadakaluru, S.; Thongsuwan, W.; Singjai, P. Stretchable and flexible high-strain sensors made using carbon nanotubes and graphite films on natural rubber. Sensors 2014, 14, 868-876. [CrossRef]

124. Shanshan, Y.; Yong, Z. Wearable multifunctional sensors using printed stretchable conductors made of silver nanowires. Nanoscale 2014, 6, 2345-2352.

125. Pang, Y.; Tian, H.; Tao, L.; Li, Y.; Wang, X.; Deng, N.; Yang, Y.; Ren, T.L. Flexible, Highly Sensitive, and Wearable Pressure and Strain Sensors with Graphene Porous Network Structure. ACS Appl. Mater. Interfaces 2016, 8, 26458-26462. [CrossRef] [PubMed]

126. Li, X.; Hua, T.; Xu, B. Electromechanical properties of a yarn strain sensor with graphene-sheath/ polyurethane-core. Carbon 2017, 118, 686-698. [CrossRef]

127. Qiu, L.; Liu, J.Z.; Chang, S.L.; Wu, Y.; Li, D. Biomimetic superelastic graphene-based cellular monoliths. Nat. Commun. 2012, 3, 1241. [CrossRef] [PubMed]

128. Liu, C.X.; Choi, J.W. Analyzing resistance response of embedded PDMS and carbon nanotubes composite under tensile strain. Microelectron. Eng. 2014, 117, 1-7. [CrossRef]

129. Zhang, R.; Deng, H.; Valenca, R.; Jin, J.; Fu, Q.; Bilotti, E.; Peijs, T. Strain sensing behaviour of elastomeric composite films containing carbon nanotubes under cyclic loading. Compos. Sci. Technol. 2013, 74, 1-5. [CrossRef]

130. Yu, R.J.; Park, H.; Jin, S.W.; Hong, S.Y.; Lee, S.S.; Ha, J.S. Highly Stretchable and Sensitive Strain Sensors Using Fragmentized Graphene Foam. Adv. Funct. Mater. 2015, 25, 4228-4236.

131. Deng, H.; Ji, M.; Yan, D.; Fu, S.; Duan, L.; Zhang, M.; Fu, Q. Towards tunable resistivity-strain behavior through construction of oriented and selectively distributed conductive networks in conductive polymer composites. J. Mater. Chem. 2014, 2, 10048-10058. [CrossRef]

132. Hempel, M.; Nezich, D.; Kong, J.; Hofmann, M. A novel class of strain gauges based on layered percolative films of 2D materials. Nano Lett. 2012, 12, 5714-5718. [CrossRef] [PubMed]

133. Zhao, H.; Bai, J. Highly sensitive piezo-resistive graphite nanoplatelet-carbon nanotube hybrids/ polydimethylsilicone composites with improved conductive network construction. ACS Appl. Mater. Interfaces 2015, 7, 9652-9659. [CrossRef] [PubMed]

134. Shi, G.; Zhao, Z.; Pai, J.-H.; Lee, I.; Zhang, L.; Stevenson, C.; Ishara, K.; Zhang, R.; Zhu, H.; Ma, J. Highly Sensitive, Wearable, Durable Strain Sensors and Stretchable Conductors Using Graphene/Silicon Rubber Composites. Adv. Funct. Mater. 2016, 26, 7614-7625. [CrossRef]

135. Rinaldi, A.; Tamburrano, A.; Fortunato, M.; Sarto, M.S. A Flexible and Highly Sensitive Pressure Sensor Based on a PDMS Foam Coated with Graphene Nanoplatelets. Sensors 2016, 16, 2148. [CrossRef] [PubMed]

136. Shi, X.; Liu, S.; Sun, Y.; Liang, J.; Chen, Y. Lowering Internal Friction of 0D-1D-2D Ternary Nanocomposite-Based Strain Sensor by Fullerene to Boost the Sensing Performance. Adv. Funct. Mater. 2018, 28, 1800850. [CrossRef]

137. Cheng, Y.; Wang, R.; Sun, J.; Gao, L. A Stretchable and Highly Sensitive Graphene-Based Fiber for Sensing Tensile Strain, Bending, and Torsion. Adv. Mater. 2015, 27, 7365-7371. [CrossRef] [PubMed]

138. Wang, C.; Li, X.; Gao, E.; Jian, M.; Xia, K.; Wang, Q.; Xu, Z.; Ren, T.; Zhang, Y. Carbonized Silk Fabric for Ultrastretchable, Highly Sensitive, and Wearable Strain Sensors. Adv. Mater. 2016, 28, 6640-6648. [CrossRef] [PubMed]

139. Li, Q.; Ullah, Z.; Li, W.; Guo, Y.; Xu, J.; Wang, R.; Zeng, Q.; Chen, M.; Liu, C.; Liu, L. Wide-Range Strain Sensors Based on Highly Transparent and Supremely Stretchable Graphene/Ag-Nanowires Hybrid Structures. Small 2016, 12, 5058-5065. [CrossRef]

140. Song, H.; Zhang, J.; Chen, D.; Wang, K.; Niu, S.; Han, Z.; Ren, L. Superfast and high-sensitivity printable strain sensors with bioinspired micron-scale cracks. Nanoscale 2016, 9, 1166-1173. [CrossRef] [PubMed]

141. Tingting, Y.; Wen, W.; Hongze, Z.; Xinming, L.; Jidong, S.; Yijia, H.; Quan-Shui, Z.; Zhihong, L.; Hongwei, Z. Tactile Sensing System Based on Arrays of Graphene Woven Microfabrics: Electromechanical Behavior and Electronic Skin Application. ACS Nano 2015, 9, 10867-10875.

142. Zhang, R.; Hu, R.; Li, X.; Zhen, Z.; Xu, Z.; Li, N.; He, L.; Zhu, H. A Bubble-Derived Strategy to Prepare Multiple Graphene-Based Porous Materials. Adv. Funct. Mater. 2018, 28, 1705879. [CrossRef] 
143. Long, Y.; Zhao, X.; Jiang, X.; Zhang, L.; Zhang, H.; Liu, Y.; Zhu, H. A porous graphene/polydimethylsiloxane composite by chemical foaming for simultaneous tensile and compressive strain sensing. FlatChem 2018, 10, 1-7. [CrossRef]

144. Oren, S.; Ceylan, H.; Liang, D. Helical-Shaped Graphene Tubular Spring Formed within Microchannel for Wearable Strain Sensor with Wide Dynamic Range. IEEE Sens. Lett. 2017, 1, 1-4. [CrossRef]

145. Li, X.; Yang, T.; Yang, Y.; Zhu, J.; Li, L.; Alam, F.E.; Li, X.; Wang, K.; Cheng, H.; Lin, C.-T.; et al. Large-Area Ultrathin Graphene Films by Single-Step Marangoni Self-Assembly for Highly Sensitive Strain Sensing Application. Adv. Funct. Mater. 2016, 26, 1322-1329. [CrossRef]

146. Lou, Z.; Chen, S.; Wang, L.; Jiang, K.; Shen, G. An ultra-sensitive and rapid response speed graphene pressure sensors for electronic skin and health monitoring. Nano Energy 2016, 23, 7-14. [CrossRef]

147. Tian, H.; Shu, Y.; Wang, X.F.; Mohammad, M.A.; Bie, Z.; Xie, Q.Y.; Li, C.; Mi, W.T.; Yang, Y.; Ren, T.L. A graphene-based resistive pressure sensor with record-high sensitivity in a wide pressure range. Sci. Rep. 2015, 5, 8603. [CrossRef] [PubMed]

148. Jian, M.; Xia, K.; Wang, Q.; Yin, Z.; Wang, H.; Wang, C.; Xie, H.; Zhang, M.; Zhang, Y. Flexible and Highly Sensitive Pressure Sensors Based on Bionic Hierarchical Structures. Adv. Funct. Mater. 2017, 27, 1606066. [CrossRef]

149. Chen, W.; Gui, X.; Liang, B.; Yang, R.; Zheng, Y.; Zhao, C.; Li, X.; Zhu, H.; Tang, Z. Structural Engineering for High Sensitivity, Ultrathin Pressure Sensors Based on Wrinkled Graphene and Anodic Aluminum Oxide Membrane. ACS Appl. Mater. Interfaces 2017, 9, 24111-24117. [CrossRef] [PubMed]

150. Liu, S.; Wu, X.; Zhang, D.; Guo, C.; Wang, P.; Hu, W.; Li, X.; Zhou, X.; Xu, H.; Luo, C.; et al. Ultrafast Dynamic Pressure Sensors Based on Graphene Hybrid Structure. ACS Appl. Mater. Interfaces 2017, 9, 24148-24154. [CrossRef] [PubMed]

151. Ma, Y.; Yue, Y.; Zhang, H.; Cheng, F.; Zhao, W.; Rao, J.; Luo, S.; Wang, J.; Jiang, X.; Liu, Z.; et al. 3D Synergistical MXene/Reduced Graphene Oxide Aerogel for a Piezoresistive Sensor. ACS Nano 2018, 12, 3209-3216. [CrossRef] [PubMed]

152. Chun, S.; Hong, A.; Choi, Y.; Ha, C.; Park, W. A tactile sensor using a conductive graphene-sponge composite. Nanoscale 2016, 8, 9185-9192. [CrossRef] [PubMed]

153. Yang, J.; Ye, Y.; Li, X.; Lü, X.; Chen, R. Flexible, conductive, and highly pressure-sensitive graphene-polyimide foam for pressure sensor application. Compos. Sci. Technol. 2018, 164, 187-194. [CrossRef]

154. Deng, W.; Fang, Q.; Huang, H.; Zhou, X.; Ma, J.; Liu, Z. Oriented Arrangement: The Origin of Versatility for Porous Graphene Materials. Small 2017, 13. [CrossRef] [PubMed]

155. Tao, L.Q.; Zhang, K.N.; Tian, H.; Liu, Y.; Wang, D.Y.; Chen, Y.Q.; Yang, Y.; Ren, T.L. Graphene-Paper Pressure Sensor for Detecting Human Motions. ACS Nano 2017, 11, 8790-8795. [CrossRef]

156. Xia, K.; Wang, C.; Jian, M.; Wang, Q.; Zhang, Y. CVD growth of fingerprint-like patterned 3D graphene film for an ultrasensitive pressure sensor. Nano Res. 2017, 11, 1124-1134. [CrossRef]

157. Garain, S.; Jana, S.; Sinha, T.K.; Mandal, D. Design of In Situ Poled Ce(3+)-Doped Electrospun PVDF/Graphene Composite Nanofibers for Fabrication of Nanopressure Sensor and Ultrasensitive Acoustic Nanogenerator. ACS Appl. Mater. Interfaces 2016, 8, 4532-4540. [CrossRef]

158. Habibi, M.; Darbari, S.; Rajabali, S.; Ahmadi, V. Fabrication of a graphene-based pressure sensor by utilising field emission behavior of carbon nanotubes. Carbon 2016, 96, 259-267. [CrossRef]

159. Shi, J.; Li, X.; Cheng, H.; Liu, Z.; Zhao, L.; Yang, T.; Dai, Z.; Cheng, Z.; Shi, E.; Yang, L.; et al. Graphene Reinforced Carbon Nanotube Networks for Wearable Strain Sensors. Adv. Funct. Mater. 2016, 26, 2078-2084. [CrossRef]

160. Hu, D.; Wang, Q.; Yu, J.; Hao, W.; Lu, H.; Zhang, G.; Wang, X.; Qiu, L. Highly Stretchable Strain Sensors Using an Electrospun Polyurethane Nanofiber/Graphene Composite. J. Nanosci. Nanotechnol. 2016, 16, 5839-5842. [CrossRef]

161. Ai, Y.; Lou, Z.; Li, L.; Chen, S.; Park, H.S.; Wang, Z.M.; Shen, G. Meters-Long Flexible CoNiO2-Nanowires@Carbon-Fibers Based Wire-Supercapacitors for Wearable Electronics. Adv. Mater. Technol. 2016, 1, 1600142. [CrossRef]

162. Li, R.; Si, Y.; Zhu, Z.; Guo, Y.; Zhang, Y.; Pan, N.; Sun, G.; Pan, T. Supercapacitive Iontronic Nanofabric Sensing. Adv. Mater. 2017, 29, 1700253. [CrossRef] [PubMed] 
163. Park, J.J.; Hyun, W.J.; Mun, S.C.; Park, Y.T.; Park, O.O. Highly stretchable and wearable graphene strain sensors with controllable sensitivity for human motion monitoring. ACS Appl. Mater. Interfaces 2015, 7, 6317-6324. [CrossRef] [PubMed]

164. Park, J.; Kim, M.; Lee, Y.; Lee, H.S.; Ko, H. Fingertip skin-inspired microstructured ferroelectric skins discriminate static/dynamic pressure and temperature stimuli. Sci. Adv. 2015, 1, e1500661. [CrossRef] [PubMed]

165. Liu, J.; Galpaya, D.; Notarianni, M.; Yan, C.; Motta, N. Graphene-based thin film supercapacitor with graphene oxide as dielectric spacer. Appl. Phys. Lett. 2013, 103, 063108. [CrossRef]

166. Boland, C.S.; Umar, K.; Claudia, B.; Arlene, O.N.; Joe, M.C.; Shane, D.; Ravi, S.; Yang, L.; Izabela, J.; Dalton, A.B. Sensitive, high-strain, high-rate bodily motion sensors based on graphene-rubber composites. ACS Nano 2014, 8, 8819. [CrossRef] [PubMed]

167. Yi, W.; Rong, Y.; Zhiwen, S.; Lianchang, Z.; Dongxia, S.; Enge, W.; Guangyu, Z. Super-elastic graphene ripples for flexible strain sensors. ACS Nano 2011, 5, 3645-3650.

168. Choi, Y.W.; Kang, D.; Pikhitsa, P.V.; Lee, T.; Kim, S.M.; Lee, G.; Tahk, D.; Choi, M. Ultra-sensitive Pressure sensor based on guided straight mechanical cracks. Sci. Rep. 2017, 7, 40116. [CrossRef] [PubMed]

169. Liu, F.; Seo, T.S. A Controllable Self-Assembly Method for Large-Scale Synthesis of Graphene Sponges and Free-Standing Graphene Films. Adv. Funct. Mater. 2010, 20, 1930-1936. [CrossRef]

170. Li, C.; Shi, G. Three-dimensional graphene architectures. Nanoscale 2012, 4, 5549-5563. [CrossRef]

171. Cao, X.; Yin, Z.; Zhang, H. Three-dimensional graphene materials: Preparation, structures and application in supercapacitors. Energy Environ. Sci. 2014, 7, 1850-1865. [CrossRef]

172. Wu, Y.; Yi, N.; Huang, L.; Zhang, T.; Fang, S.; Chang, H.; Li, N.; Oh, J.; Lee, J.A.; Kozlov, M.; et al. Three-dimensionally bonded spongy graphene material with super compressive elasticity and near-zero Poisson's ratio. Nat. Commun. 2015, 6, 6141. [CrossRef] [PubMed]

173. Li, W.; Guo, J.; Fan, D. 3D Graphite-Polymer Flexible Strain Sensors with Ultrasensitivity and Durability for Real-Time Human Vital Sign Monitoring and Musical Instrument Education. Adv. Mater. Technol. 2017, 2, 1700070. [CrossRef]

174. Ai, Y.; Lou, Z.; Chen, S.; Chen, D.; Wang, Z.M.; Jiang, K.; Shen, G. All rGO-on-PVDF-nanofibers based self-powered electronic skins. Nano Energy 2017, 35, 121-127. [CrossRef]

175. Shehzad, K.; Shi, T.; Qadir, A.; Wan, X.; Guo, H.; Ali, A.; Xuan, W.; Xu, H.; Gu, Z.; Peng, X.; et al. Designing an Efficient Multimode Environmental Sensor Based on Graphene-Silicon Heterojunction. Adv. Mater. Technol. 2017, 2, 1600262. [CrossRef]

176. Ghosh, S.K.; Adhikary, P.; Jana, S.; Biswas, A.; Sencadas, V.; Gupta, S.D.; Tudu, B.; Mandal, D. Electrospun gelatin nanofiber based self-powered bio-e-skin for health care monitoring. Nano Energy 2017, 36, 166-175. [CrossRef]

177. Wei, Y.; Chen, S.; Dong, X.; Lin, Y.; Liu, L. Flexible piezoresistive sensors based on "dynamic bridging effect" of silver nanowires toward graphene. Carbon 2017, 113, 395-403. [CrossRef]

178. He, H.; Fu, Y.; Zang, W.; Wang, Q.; Xing, L.; Zhang, Y.; Xue, X. A flexible self-powered T-ZnO/PVDF/fabric electronic-skin with multi-functions of tactile-perception, atmosphere-detection and self-clean. Nano Energy 2017, 31, 37-48. [CrossRef]

179. Gong, S.; Lai, D.T.H.; Su, B.; Si, K.J.; Ma, Z.; Yap, L.W.; Guo, P.; Cheng, W. Highly Stretchy Black Gold E-Skin Nanopatches as Highly Sensitive Wearable Biomedical Sensors. Adv. Electron. Mater. 2015, 1, 1400063. [CrossRef]

180. Lou, Z.; Chen, S.; Wang, L.; Shi, R.; Li, L.; Jiang, K.; Chen, D.; Shen, G. Ultrasensitive and ultraflexible e-skins with dual functionalities for wearable electronics. Nano Energy 2017, 38, 28-35. [CrossRef]

181. Pang, Y.; Zhang, K.; Yang, Z.; Jiang, S.; Ju, Z.; Li, Y.; Wang, X.; Wang, D.; Jian, M.; Zhang, Y.; et al. Epidermis Microstructure Inspired Graphene Pressure Sensor with Random Distributed Spinosum for High Sensitivity and Large Linearity. ACS Nano 2018, 12, 2346-2354. [CrossRef]

182. An, B.W.; Heo, S.; Ji, S.; Bien, F.; Park, J.U. Transparent and flexible fingerprint sensor array with multiplexed detection of tactile pressure and skin temperature. Nat. Commun. 2018, 9, 2458. [CrossRef] [PubMed]

183. Yang, T.; Jiang, X.; Zhong, Y.; Zhao, X.; Lin, S.; Li, J.; Li, X.; Xu, J.; Li, Z.; Zhu, H. A Wearable and Highly Sensitive Graphene Strain Sensor for Precise Home-Based Pulse Wave Monitoring. ACS Sens. 2017, 2, 967-974. [CrossRef] [PubMed] 
184. Yeo, J.C.; Liu, Z.; Zhang, Z.-Q.; Zhang, P.; Wang, Z.; Lim, C.T. Wearable Mechanotransduced Tactile Sensor for Haptic Perception. Adv. Mater. Technol. 2017, 2, 1700006. [CrossRef]

185. Available online: http:/ /www.51yuansu.com/sc/vjrfxfaxfi.html (accessed on 26 September 2017).

186. Available online: http://wuxia.wikia.com/wiki/Guo_Jing (accessed on 12 March 2019).

187. Available online: http://www.wfeng.cn/gongfu/wushuxiangguan/gongfuzhexue/201805/10905.html (accessed on 22 May 2018).

188. Available online: http:/ / 616pic.com/sucai/158idlp6m.html (accessed on 12 March 2019).

189. Available online: http://www.dzwww.com/2016/2016aqyyy/yakp/201711/t20171101_16599166.htm (accessed on 1 November 2017).

190. Available online: https://www.123rf.com/clipartvector/oscilloscope.html?sti=malzoro6g7ixad8ui1 \T1 textbar\{\}\&mediapopup=72121187 (accessed on 12 March 2019).

191. Available online: https:/ / health.ifeng.com/c/7i3rCzx0Yki (accessed on 23 November 2018).

192. Available online: https://pngtree.com/freepng/brucelee_1231266.html (accessed on 12 March 2019).

193. Liu, H.; Guo, K.; Zhang, Z.; Yu, D.; Zhang, J.; Ning, P.; Cheng, J.; Li, X.; Niu, P. High-Power LED Photoelectrothermal Analysis Based on Backpropagation Artificial Neural Networks. IEEE Trans. Electron Devices 2017, PP, 1-7. [CrossRef]

194. Tian, H.; Wang, X.F.; Mohammad, M.A.; Gou, G.Y.; Wu, F.; Yang, Y.; Ren, T.L. A hardware Markov chain algorithm realized in a single device for machine learning. Nat. Commun. 2018, 9, 4305. [CrossRef] [PubMed]

195. Hua, Q.; Sun, J.; Liu, H.; Bao, R.; Yu, R.; Zhai, J.; Pan, C.; Wang, Z.L. Skin-inspired highly stretchable and conformable matrix networks for multifunctional sensing. Nat. Commun. 2018, 9, 244. [CrossRef] [PubMed]

196. Xie, D.; Jiang, J.; Hu, W.; He, Y.; Yang, J.; He, J.; Gao, Y.; Wan, Q. Coplanar Multigate MoS2 Electric-DoubleLayer Transistors for Neuromorphic Visual Recognition. ACS Appl. Mater. Interfaces 2018, 10, 25943-25948. [CrossRef] [PubMed]

197. Kim, J.; Lee, M.; Shim, H.J.; Ghaffari, R.; Cho, H.R.; Son, D.; Jung, Y.H.; Soh, M.; Choi, C.; Jung, S.; et al. Stretchable silicon nanoribbon electronics for skin prosthesis. Nat. Commun. 2014, 5, 5747. [CrossRef] [PubMed] 